Prepared in cooperation with the Bureau of Reclamation

\title{
Particle-Tracking Investigation of the Retention of Sucker Larvae Emerging from Spawning Grounds in Upper Klamath Lake, Oregon
}

Open-File Report 2014-1061 



\section{Particle-Tracking Investigation of the Retention of Sucker Larvae Emerging from Spawning Grounds in Upper Klamath Lake, Oregon}

By Tamara M. Wood, Susan A. Wherry, David C. Simon, and Douglas F. Markle

Prepared in cooperation with the Bureau of Reclamation

Open-File Report 2014-1061 


\section{U.S. Department of the Interior \\ SALLYJEWELL, Secretary}

\section{U.S. Geological Survey \\ Suzette M. Kimball, Acting Director}

U.S. Geological Survey, Reston, Virginia: 2014

For more information on the USGS-the Federal source for science about the Earth,

its natural and living resources, natural hazards, and the environment-visit

http://www.usgs.gov or call 1-888-ASK-USGS

For an overview of USGS information products, including maps, imagery, and publications, visit $h$ ttp://www.usgs.gov/pubprod

To order this and other USGS information products, visit http://store.usgs.gov

Suggested citation:

Wood, T.M, Wherry, S.A., Simon, D.C., and Markle,D.F. , 2014, Particle-tracking investigation of the retention of sucker larvae emerging from spawning grounds in Upper Klamath Lake, Oregon: U.S. Geological Survey Open-File Report 2014-1061, 44 p., http://dx.doi.org/10.3133/ofr20141061.

ISSN 2331-1258 (online)

Any use of trade, product, or firm names is for descriptive purposes only and does not imply endorsement by the U.S. Government.

Although this report is in the public domain, permission must be secured from the individual copyright owners to reproduce any copyrighted material contained within this report. 


\section{Contents}



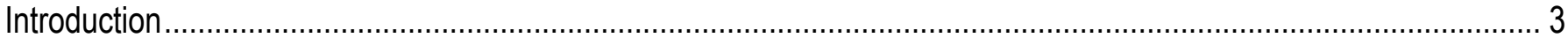

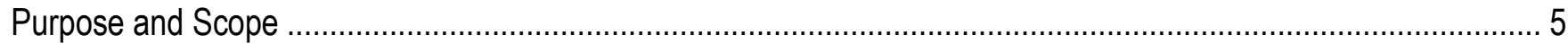

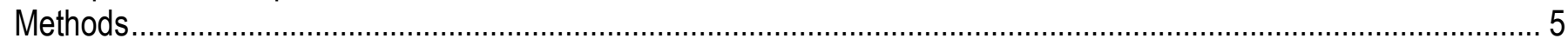

Comparison of Particle-Tracking Results with Net Catches ...................................................................... 5

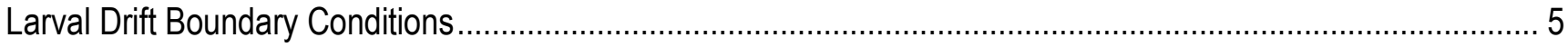

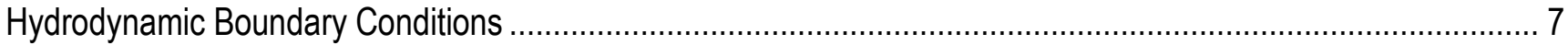

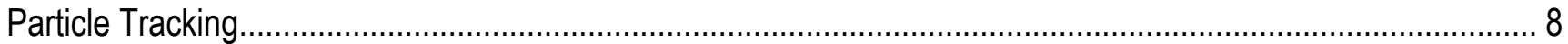

Comparison of Particle-Tracking Results to Field Data ............................................................................

Sensitivity of Particle Retention to Wind, River Discharge, and Lake Elevation ..................................................10

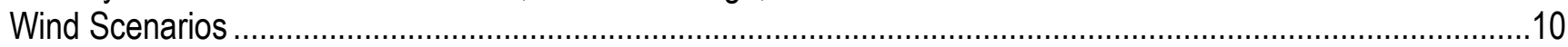

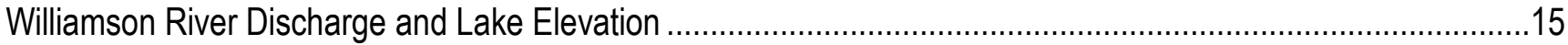

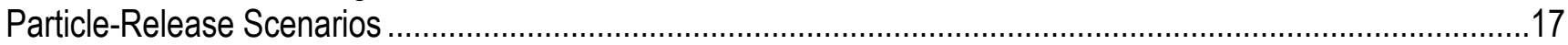

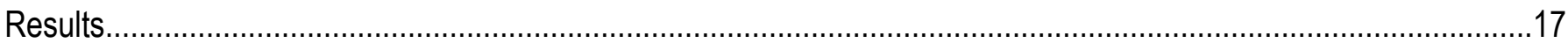

Larval Drift Boundary Conditions ..........................................................................................................

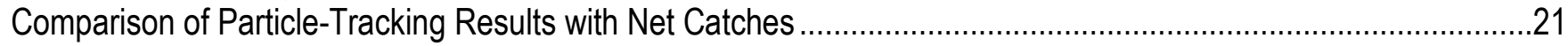

Sensitivity of Particle Retention to Wind, River Discharge, and Lake Elevation ....................................................34

Particle Retention-Spawning at Springs..........................................................................................

Particle Retention-Spawning in Williamson River ................................................................................36

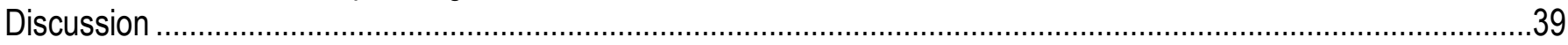

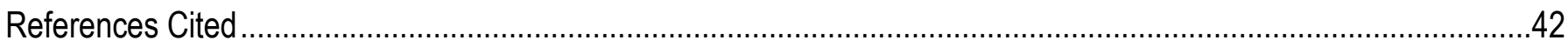

Appendix A. Animations of Particle Tracking Simulations, April-June, 2011-12 ……...........................................44

\section{Figures}

Figure 1. Map showing sites where gage, meteorological, and fish data used to run the individual-based model of larval sucker retention in Upper Klamath and Agency Lakes, Oregon were collected.

Figure 2. Monthly wind roses from site Williamson River West (WRW-MET, U.S. Geological Survey station 422807121572500), Upper Klamath Lake, Oregon, April 2008-June 2011.

Figure 3. Wind roses from site Williamson River West (WRW_MET, U.S. Geological Survey station 422807121572500), Upper Klamath Lake, Oregon, for 15-day segments corresponding to wind scenarios for release of particles from spawning grounds at eastern shoreline springs.

Figure 4. Wind roses at site Williamson River West (WRW-MET, U.S. Geological Survey station 422807121572500), Oregon, for 25-day segments corresponding to wind scenarios for release of particles from spawning grounds in the Williamson and Sprague Rivers.

Figure 5. Graphs showing simulated and observed Lost River larval sucker (LRS) densities at the Modoc Point Road bridge in the Williamson River, Oregon, 2007-2010.

Figure 6. Graphs showing simulated and observed shortnose larval sucker (SNS) densities at the Modoc Point Road bridge in the Williamson River, Oregon, 2007-2010.

Figure 7. Graphs showing simulated Lost River sucker (LRS) and shortnose sucker (SNS) larval drift boundary conditions at Modoc Point Road bridge and eastern shoreline springs compared to cumulative adult female fish counts in 2011 and 2012, and daily adult female fish counts in 2011 and 2012, Upper Klamath Lake, Oregon....... 20 
Figure 8. Maps showing spatial distribution of particles from the particle-tracking simulation on two dates straddling each of two larval trawl surveys in 2011, and fish density observed in nets during each survey of Lost River (LRS) and shortnose sucker larvae (SNS), Upper Klamath Lake, Oregon.

Figure 9. Maps showing spatial distribution of particles from the particle-tracking simulation on two dates straddling each of two larval trawl surveys in 2012, and fish density observed in nets during each survey of Lost River (LRS) and shortnose sucker larvae (SNS), Upper Klamath Lake, Oregon.

Figure 10. Weekly catch per unit effort (CPUE) of particles representing (A) Lost River sucker (LRS) larvae, and (B) shortnose sucker (SNS) larvae, and CPUE of larvae caught in nets during two larval trawl surveys in 2011, in each of five zones in Upper Klamath Lake, Oregon.

Figure 11. Weekly catch per unit effort (CPUE) of particles representing $(A)$ Lost River sucker (LRS) larvae, and $(B)$ shortnose sucker (SNS) larvae, and CPUE of larvae caught in nets during two larval trawl surveys in 2012, in each of five zones in Upper Klamath Lake, Oregon.

Figure 12. Boxplots showing weekly length distributions of Lost River sucker larvae in 2011, as determined from particle-tracking simulations and from larval trawls, Upper Klamath Lake, Oregon.

Figure 13. Boxplots showing weekly length distributions of Lost River sucker larvae in 2012, as determined from particle-tracking simulations and from larval trawls, Upper Klamath Lake, Oregon.

Figure 14. Boxplots showing weekly length distributions of shortnose sucker larvae in 2011, as determined from particle-tracking simulations and fro Whiskers on boxes are 1.5 times the interquartile range.

Figure 15. Boxplots showing weekly length distributions of shortnose sucker larvae in 2012, as determined from particle-tracking simulations and from larval trawls, Upper Klamath Lake, Oregon.

Figure 16. Graph showing fraction of particles that exited the model domain as a function of time since the particle group was inserted into the simulation, for particle groups inserted at eastern shoreline springs, Upper Klamath Lake, Oregon......

Figure 17. Graph showing fraction of particles that exited the model domain as a function of time since the particle group was inserted into the simulation, for particle group S1, inserted at eastern shoreline springs, Upper Klamath Lake, Oregon.

Figure 18. Graph showing fraction of particles that exited the model domain as a function of time since the particle group was inserted into the simulation, for particle group S1, inserted at eastern shoreline springs, Upper Klamath Lake, Oregon.

Figure 19. Graph showing fraction of particles that exited the model domain as a function of time since the particle group was inserted into the simulation, for particle groups inserted at the Williamson River boundary, Upper Klamath Lake, Oregon.

Figure 20. Graph showing fraction of particles that exited the model domain as a function of time since the particle group was inserted into the simulation, for particle group R1, inserted at the Williamson River boundary, Upper Klamath Lake, Oregon.

Figure 21. Graph showing fraction of particles that exited the model domain as a function of time since the particle group was inserted into the simulation, for particle group R1, inserted at the Williamson River boundary, Upper Klamath Lake, Oregon. 


\section{Tables}

Table 1. Selected characteristics of wind data collected at U.S. Geological Survey meteorological station 422807121572500, Williamson River West, Oregon, April 2008-June 2011.

Table 2. Selected percentiles of monthly mean discharge data for the Williamson River (U.S. Geological Survey station 11502500) and stage data for Upper Klamath Lake (U.S. Geological Survey station 11507001), Oregon, March-June 1975-2012.

Table 3. Catch per unit effort (CPUE) of Lost River sucker and shortnose sucker larvae, as determined from 20112012 particle tracking simulations and larval trawls, Upper Klamath Lake, Oregon. 25

Table 4. Median length of Lost River and shortnose sucker larvae (in millimeters), as determined from particletracking simulations and from larval trawls, Upper Klamath Lake, Oregon, 2011-12.

Table 5. Spearman correlation coefficients relating the simulated length of Lost River sucker (LRS) and shortnose sucker (SNS) larvae, as determined from particle tracking simulations to the length of Lost River and shortnose sucker larvae caught in larval trawls, Upper Klamath Lake, Oregon.....

Table 6. Fraction of particles that has exited the model domain by 6,10 , and 15 days since the particle group was inserted into the model simulation (blue bars), as a function of Upper Klamath Lake elevation and Williamson River discharge, for particle groups inserted at eastern shoreline springs, Upper Klamath Lake, Oregon. 36

Table 7. Fraction of particles that have exited the model domain as of 10,15 , and 25 days since the particle group was inserted into the simulation (blue bars), as a function of Upper Klamath Lake elevation and Williamson River discharge, for particle groups inserted at spawning grounds in the Williamson and Sprague Rivers, Oregon

\section{Conversion Factors and Datums}

\section{Conversion Factors}

Inch/Pound to SI

\begin{tabular}{|c|c|c|}
\hline Multiply & By & To obtain \\
\hline foot $(\mathrm{ft})$ & 0.3048 & meter $(\mathrm{m})$ \\
\hline cubic foot per second $\left(\mathrm{ft}^{3} / \mathrm{s}\right)$ & 0.02832 & cubic meter per second $(\mathrm{m} 3 / \mathrm{s})$ \\
\hline
\end{tabular}

SI to Inch/Pound

\begin{tabular}{lll}
\hline \multicolumn{1}{c}{ Multiply } & \multicolumn{1}{c}{ By } & \multicolumn{1}{c}{ To obtain } \\
\hline millimeter $(\mathrm{mm})$ & 0.03937 & inch (in.) \\
centimeter $(\mathrm{cm})$ & 0.3937 & inch (in.) \\
meter $(\mathrm{m})$ & 3.281 & foot (ft) \\
kilometer $(\mathrm{km})$ & 0.6214 & mile (mi) \\
meter per second $(\mathrm{m} / \mathrm{s})$ & 3.281 & foot per second (ft/s) \\
cubic meter per second $\left(\mathrm{m}^{3} / \mathrm{s}\right)$ & 70.07 & acre-foot per day (acre-ft/d) \\
\hline
\end{tabular}




\section{Datums}

Vertical coordinate information is referenced to the Bureau of Reclamation datum, which is 1.78 feet above National Geodetic Vertical Datum of 1929 (NGVD 29).

Horizontal coordinate information is referenced to the North American Datum of 1927 (NAD 27).

Elevation, as used in this report, refers to distance above the vertical datum. 


\title{
Particle-Tracking Investigation of the Retention of Sucker Larvae Emerging from Spawning Grounds in Upper Klamath Lake, Oregon
}

\author{
By Tamara M. Wood ${ }^{1}$, Susan A. Wherry ${ }^{1}$, David C. Simon ${ }^{2}$, and Douglas F. Markle ${ }^{2}$
}

\section{Executive Summary}

This study had two objectives: (1) to use the results of an individual-based particle-tracking model of larval sucker dispersal through the Williamson River delta and Upper Klamath Lake, Oregon, to interpret field data collected throughout Upper Klamath and Agency Lakes, and (2) to use the model to investigate the retention of sucker larvae in the system as a function of Williamson River flow, wind, and lake elevation. This is a follow-up study to work reported in Wood and others (2014) in which the hydrodynamic model of Upper Klamath Lake was combined with an individual-based, particletracking model of larval fish entering the lake from spawning areas in the Williamson River. In the previous study, the performance of the model was evaluated through comparison with field data comprising larval sucker distribution collected in 2009 by The Nature Conservancy, Oregon State University (OSU), and the U.S. Geological Survey, primarily from the (at that time) recently reconnected Williamson River Delta and along the eastern shoreline of Upper Klamath Lake, surrounding the old river mouth. The previous study demonstrated that the validation of the model with field data was moderately successful and that the model was useful for describing the broad patterns of larval dispersal from the river, at least in the areas surrounding the river channel immediately downstream of the spawning areas and along the shoreline where larvae enter the lake.

\footnotetext{
${ }^{1}$ U.S. Geological Survey

${ }^{2}$ Oregon State University
}

In this study, field data collected by OSU throughout the main body of Upper Klamath Lake, and not just around the Williamson River Delta, were compared to model simulation results. Because the field data were collected throughout the lake, it was necessary to include in the simulations larvae spawned at eastern shoreline springs that were not included in the earlier studies. A complicating factor was that the OSU collected data throughout the main body of the lake in 2011 and 2012, after the end of several years of larval drift collection in the Williamson River by the U.S. Geological Survey. Those larval drift data provided necessary boundarycondition information for the earlier studies, but there were no measured boundary conditions for larval input into model simulations during the years of this study (2011-12). Therefore, we developed a method to estimate a time series of larval drift in the Williamson River, and of the emergence of larvae from the gravel at the eastern shoreline springs, that captured the approximate timing of the larval pulse of the Lost River sucker (Deltistes luxatus) and shortnose sucker (Chasmistes brevirostris) and the relative magnitude of the pulses by species and spawning location. The method is not able to predict larval drift on any given day, but it can reasonably predict the approximate temporal progression of the larval drift through the season, based on counts of adult suckers returning to spawn. The accuracy in the timing of the larval pulses is not better than about plus or minus 5 days.

Model results and field data were consistent in the basic progression of both catch per unit effort (CPUE) and larval length through time. The 
model simulation results also duplicated some of the characteristics of the spatial patterns of density in the field data, notably the tendency for high larval densities closer to the eastern and western shorelines. However, the model simulations could not explain high densities in the northern part of the lake or far into Ball Bay, locations that are far from the source of larvae in the Williamson River or eastern shoreline springs (as measured along the predominant transport pathways simulated in the model). This suggests the possibility of unaccounted-for spawning areas in the northern part of the lake and also that the period during which larvae are transported passively by the currents is shorter than the 46 days simulated in the model. Similarly, the progression of larval lengths in the field data is not a simple progression from smaller to larger fish away from sources in the river and springs, as simulated by the particle-tracking model; the smallest fish were caught at different times near the Williamson River, in the northwestern part of the lake, and in the southernmost part of the lake. This again suggests that fish may be spawning at places other than the river and eastern springs, that our understanding of larval transport is incomplete, or both.

The model was used to run 96 numerical "experiments" in which lake elevation, river discharge, and wind forcing were varied

systematically in order to investigate the sensitivity of particle retention to each variable, and with particular emphasis on the idea of managing lake elevation to control emigration. The estimates of particle retention cannot be equated directly to retention of fish larvae, primarily because there was no mortality included in the simulations, but the relative comparison of retention and emigration around the matrix of experimental conditions provided several "big picture" results:
- Variables that cannot be controlledwinds and discharge - had the largest effect on retention. For example, at the lowest river discharge ( 20 cubic meters per second), simulated retention was high regardless of wind or lake elevation, whereas at the highest river discharge (100 cubic meters per second), retention was low regardless of wind or lake elevation.

- When river discharge and wind were held constant, a higher elevation delayed the onset of the most rapid exit of particles by 1 (from the springs) to 4 (from the river) days, but did not determine overall retention. Only under the combination of conditions consisting of low discharge (50 cubic meters per second or less) and strong wind reversals for several days was there a consistent effect of lake elevation on overall retention several weeks into the simulation, and, under those conditions, retention was at the high end of the possible range regardless of lake elevation.

- Under most combinations of conditions tested, after particles had been in the system for several days, the complex interaction between wind, elevation, and river discharge resulted in particle pathways, and therefore retention, being highly variable and unpredictable, at which point controlling lake elevation could not produce a predictable result. Therefore, on the basis of the model predictions, managing lake elevation probably is not a way to reliably provide any particular level of retention. 


\section{Introduction}

Beginning in 2005, the Bureau of Reclamation (Reclamation) supported the development of a hydrodynamic and heat transport model that was calibrated to data from 2005 and 2006 (Wood and others, 2008) and used to understand the role of hydrodynamics in determining water quality in Upper Klamath Lake, Oregon. In 2008, Reclamation began supporting the extension of the model to the description of larval sucker transport out of spawning grounds in the Williamson River Basin. Two species endemic to the Upper Klamath Basin (the Lost River sucker, Deltistes luxatus, and the shortnose sucker, Chasmistes brevirostris) are endangered, and one of the biggest threats to their persistence is the lack of recruitment into the adult population. The problems of larval sucker survival and retention in the lake, therefore, are directly relevant to the viability of populations of these two species.

The U.S. Geological Survey (USGS) model was used to simulate larval transport for the years 2006-2009, spanning the time of the restoration of the Williamson River Delta, which was undertaken by The Nature Conservancy, the owner of the property, in large part to provide better rearing habitat for larval suckers. During this time dramatic changes in the shoreline of the lake occurred, starting in autumn 2007, when levees surrounding the Tulana side of the delta were breached, and again in autumn 2008, when levees surrounding the Goose Bay side of the delta were breached (fig. 1). The model has been tested and evaluated with combined larval datasets from the USGS, Oregon State University (OSU), and The Nature Conservancy collected from the Williamson River Delta and the nearby shorelines in Upper Klamath and Agency Lakes. An advec- tion-diffusion approach was used to simulate larval density and to compare to the density in net catches during the weeks of larval drift from 2006 to 2009 (Wood and others, 2012). An individual-based particle tracking approach was used to simulate larval travel times through the delta and to produce a statistical distribution of larval lengths to compare with the larval lengths in net catches, as determined from a length-at-age regression (Wood and others, 2014).

In this follow-up study, larvae collected in trawls by OSU throughout the main body of Upper Klamath Lake were compared to particletracking results outside the Williamson River Delta and the eastern shoreline surrounding the Williamson River mouth. This comparison was done to determine the extent to which model results were consistent with available field data in the open waters of the lake, and to determine whether model results could contribute to the interpretation of the field data. Larvae spawned at eastern shoreline springs that were not included in Wood and others (2014) were included in this study because they spawned downstream of the river and the delta. During the spawning season in 2011, remote antennas detected about 6,500 adult Lost River suckers at several shoreline springs and about 16,500 at several Williamson River sites (Hewitt and others, 2012). Even if the number of detections is not proportional to the population size (some individuals may have been detected at multiple locations, for example), these observations suggest that larval Lost River sucker production at springs is probably significant in comparison to river production. Only Lost River suckers spawn at shoreline springs (not shortnose suckers), and they spawn earlier at the springs than in the river. 


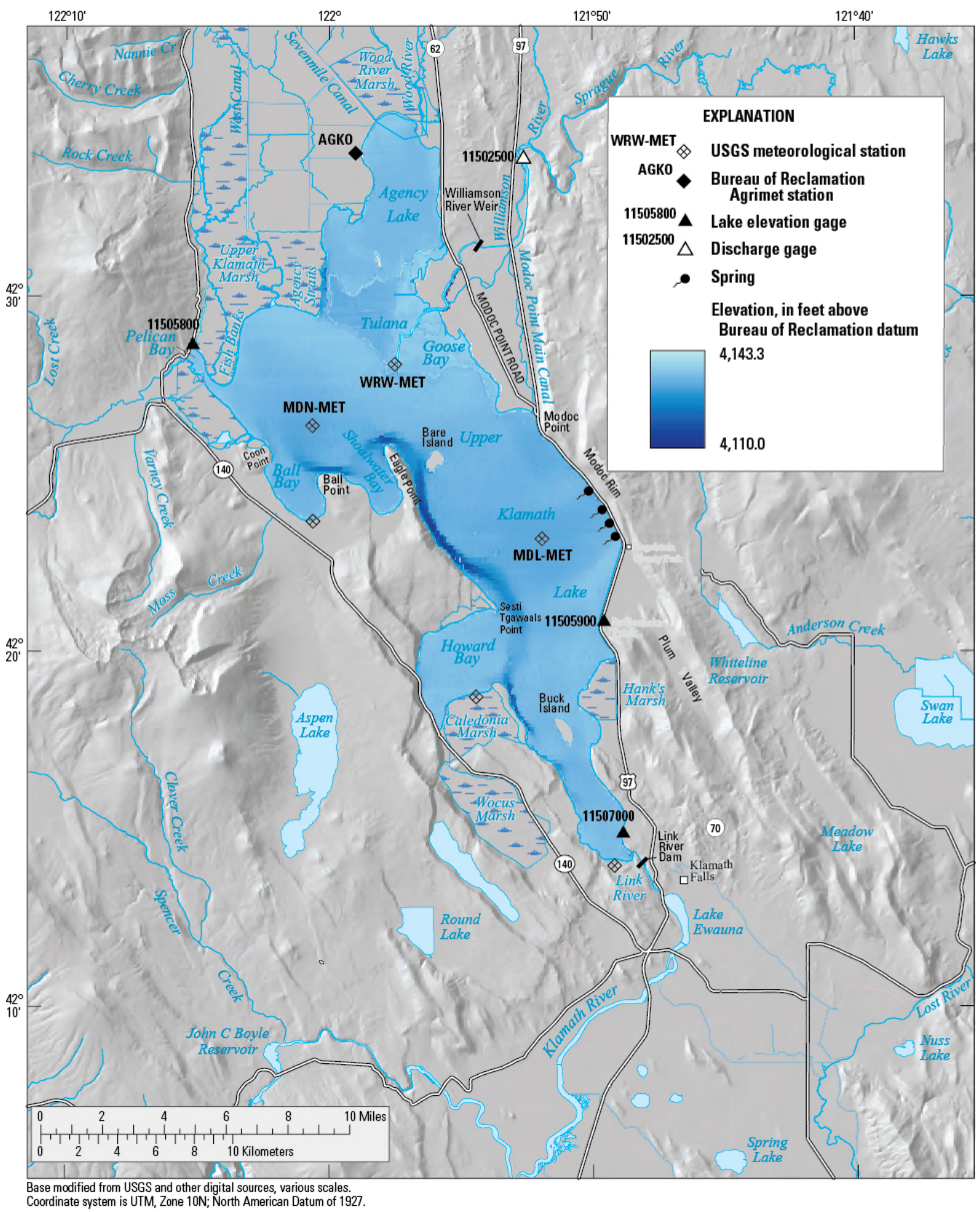

Figure 1. Map showing sites where gage, meteorological, and fish data used to run the individual-based model of larval sucker retention in Upper Klamath and Agency Lakes, Oregon, were collected. 
Lost River sucker larvae with April or May hatch dates are most likely from shoreline spring spawning and are more likely to be transported out of the lake than those with June hatch dates (Markle and others, 2009), which are most likely from river spawning. Because the larval trawl catches throughout the open waters of the lake were available beginning in 2011, and the larval drift data that were used as a boundary condition for the individual-based model in Wood and others (2014) were available only through 2010 , another necessary precursor to completing the first objective of this study was to develop an empirical model for recreating the generalized shape (length and number of pulses and the rate of increase and decrease in numbers) and timing of larval drift in the Williamson River based on the count of adult fish arriving to spawn, which is known to influence the drift (Martin and others, 2013).

An additional objective of this study was to use the model to investigate the effect of wind, river discharge, and lake elevation on the retention of larval suckers in the lake, as opposed to their loss through the outflow at the southern end of the lake. Losses of this type may be significant, particularly for species that historically depended on shoreline marshes to escape advection from the lake (Markle and others, 2009). Of particular interest is the extent to which management of the lake elevation could be used to mitigate such emigration from the lake.

\section{Purpose and Scope}

The purpose of this report is to document the three major objectives of this study: (1) to develop a method to generate a time series of larval sucker drift in the Williamson River and at the shoreline springs that describes the overall average shape and timing of the larval drift as a function of adult female count data, calibrated with 4 years of larval drift and collected during 2007-10, (2) to use the method in (1) to generate a time series of larval drift to use as a boundary condition in 2011 and 2012 to compare the simulated results of an individual-based, particle- tracking model with field data consisting of fish density and fish lengths in net catches throughout the main body of Upper Klamath and Agency Lakes, and (3) to present of the results of a series of controlled numerical "experiments" designed to quantify relative losses of drifting larvae with respect to lake elevation, Williamson River discharge, and meteorological conditions. Practical constraints limited the investigation of larval retention to four values of lake elevation between $4,140.5$ and 4,143.3 ft, four values of Williamson River discharge between 20 and 100 cubic meters per second $\left(\mathrm{m}^{3} / \mathrm{s}\right)$, and six wind-forcing scenarios (three each for release at the springs and at the river) that included strong and weak winds in both the prevailing and counter-prevailing directions.

\section{Methods}

\section{Comparison of Particle-Tracking Results with Net Catches}

\section{Larval Drift Boundary Conditions}

The individual-based model described in Wood and others (2014) requires boundary conditions that prescribe the number of larvae entering the model domain of Upper Klamath Lake at the Williamson River. Additionally, one objective of this study was to add larval drift from spawning areas in springs along the eastern shoreline that were not included in the Wood and others (2014) model. Larval drift measurements were made between 2005 and 2010 at the Modoc Point Road bridge (7.4 river km upstream of the pre-restoration mouth of the Williamson River). However, these measurements were not available during 2011-2012, when larval trawl catch data that could be used to do additional evaluation of the model's performance throughout the main body of Upper Klamath Lake were available. Furthermore, estimates or measurements of the number of larvae produced at the springs along the eastern shoreline have not been published. Therefore, as part of this study, larval sucker boundary conditions for running the individual- 
based model during 2011-12 were developed for those years using data from 2007-10. The relation between the timing of adult suckers traveling to spawn and the timing of the larval drift during years when both were available was used to create a model for a daily larval dataset at both the Williamson River boundary and the shoreline springs for spring and summer 2011-12. The daily dataset describes the generalized shape and timing of larval drift at both locations. It does not accurately describe the day-to-day variability or absolute magnitude of larval drift at either location, but describes the overall cumulative magnitude of larval fish at both locations relative to each other.

The datasets used included daily first arrival counts of adult female suckers passing the Williamson River weir at river kilometer 9.5, collected by USGS during 2007-12. These counts were detections by fixed receivers of fish into which passive integrated transponder (PIT) tags had been inserted at some time since 1995. The methods of the PIT-tagging program are summarized in Hewitt and others (2012). The adults are identified to species (Lost River, shortnose, or a third species not used in this study - the Klamath largescale sucker) at the time of tagging. The USGS also collected larval drift between March and June during 2007-10 in the thalweg of the Williamson River at the Modoc Point Road bridge; these data were expressed as density of fish per cubic meter. These larvae were identified as one of two taxa (either Lost River sucker or a fish that could be either shortnose sucker or Klamath largescale sucker, because it was not possible to distinguish between these two). In this report we use SNS, when referring to larvae, to designate a fish that is either a shortnose sucker or a Klamath largescale sucker. The details of the larval drift collection program are provided in Martin and others (2013). Because both the adult counts and the larval drift included species information, it was possible to consider the shortnose-Klamath largescale sucker (SNS) and Lost River sucker (LRS) separately in this study. Daily average Williamson River discharge used for model development was collected during 2007-2012 at USGS streamflow-gaging station 11502500 (fig. 1). As a first step in developing a model for the Williamson River drift boundary condition, the drift density measurements were converted to a daily larval count by multiplying individual net catches by Williamson River discharge and summing over 1 day.

The Williamson River larval drift model used elapsed time $(\tau)$ as the independent variable for describing the shape and timing of Lost River sucker and shortnose sucker daily larval counts at the Modoc Point Road bridge. (Elapsed time [ $\tau]$ was defined as the number of days since a specified proportion [determined by calibration] of the total yearly count of adult females was observed traveling upriver.) To capture the specific nonlinear shape that related larval counts to $\tau$, the semiparametric generalized additive model (GAM) with locally weighted scatter plot smoothing procedure was used. GAM allows the user to incorporate nonlinearities directly by modeling the independent variable with parametric and nonparametric components (Chambers and Hastie, 1992).

Larval drift data from all years (2007-2010) were combined and the larval count data, $L$, were modeled as a function of $\tau$. The GAM method fit the daily larval count data with respect to $\tau$ using a parametric (linear) approach while also incorporating a nonparametric, locally-weighted smoothed fit (LOESS) of the residuals between the observed larval counts and linear model. The simulated dataset was created by taking the sum of the parametric and nonparametric components at each $\tau$. After the two components were added, the daily larval count values were divided by the Williamson River discharge to obtain average daily larval density (as required by the particletracking model), and were multiplied by a factor of 0.39 to scale the drift collected in the thalweg to the cross-sectional average density (Wood and others, 2012). 
Two river model parameters required calibration and selection: (1) the percentage of adults passing the Williamson River weir before $\tau$ is initialized, and (2) the window span for LOESS smoothing. The adult passing percentages considered were 2, 5 and 10 percent, and the LOESS window spans considered were $0.2,0.3,0.4,0.5$ and 0.6 (fraction of all data included in the local smoothing window). All 15 parameter combinations were evaluated using a k-fold cross validation technique, with $\mathrm{k}$ equal to 4 and corresponding to a full year of observed data from 2007 to 2010, for both the Lost River sucker and shortnose sucker models. In this validation technique, the full dataset for each species during 2007-2010 was partitioned into four yearly datasets, and simulations were run using 3 years of data to develop the model and the fourth year of data to validate the model. This process was repeated four times, using a different year of the data to validate the model each time. Therefore, the entire dataset was used for validation exactly one time. The calibrated parameters were selected based on minimizing the sum of squared error between observed and simulated larval counts.

In addition to spawning at sites along the Williamson River, Lost River suckers also spawn in springs along the eastern shoreline of Upper Klamath Lake (fig. 1). Because there were no larval drift measurements at the springs to compare directly to adult counts, the timing and relative number (compared to the river) of larvae produced at the springs was determined from the count of adult females at the springs without the calibration of any parameters as follows: Larval drift at the springs was assumed to increase and decrease with the shape of a sine curve with respect to time. Based on Foott and others (2013), larvae were simulated to begin to swim up from the spawning areas and into the lake water column 14 days after $2 \%$ of the total yearly count of adult females was detected at the springs; this marked the beginning of the sine curve. The peak in the sine curve (maximum daily larval count) was determined by assuming that the ratio of total springs larvae, integrated over the season, to the total LRS river larvae entering the lake from the Williamson River, was equal to 1-to-9 (Hewitt and others, 2012). The span of the sine curve was set equal to the number of days required for the count of adult females at the springs to increase from $2 \%$ to $98 \%$ of the total adult female count in each year.

\section{Hydrodynamic Boundary Conditions}

The UnTRIM hydrodynamic model solves the governing equations for flow and transport on an orthogonal unstructured grid using the efficient and stable algorithms of Casulli and Zanolli (2002). The details of the three-dimensional Upper Klamath Lake model and its calibration and validation are provided for the years 2005 and 2006 in Wood and others (2008). The one-layer (depth-averaged) version of the hydrodynamic model that was used in this study is described in Wood and others $(2012,2013)$. Williamson River discharge was a daily average obtained from USGS streamflow-gaging station 11502500 (fig. 1); lake elevation was the daily weighted mean of the elevation measured at three water-stage gages along the shoreline (fig. 1), which is published as USGS station 11507001.

The wind forcing at the surface of the lake for 2011 and 2012, the years of simulation in this study, was not as complete and detailed as the wind data described in Wood and others (2008), because land-based meteorological stations that collected year-round data were decommissioned starting in 2010. Wind data were collected subsequently at two floating rafts, one in the northern basin of the lake and one centrally located in the main body of the lake (fig. 1), but only during the water-quality-sampling field season. Based on availability, wind data from the following sites were used to force the model: In 2011, data from the last remaining land-based meteorological station at site WRW (fig. 1) were available through July 7. Raft-based data from site MDL were available starting on June 21. Data from the second raft at MDN were available starting on August 5. The 2011 simulations in this study ran from April 16 through June 25, so a spatially uni- 
form wind forcing based on data from site WRW was used for the entire simulation. In 2012, there were no remaining land-based meteorological stations. The floating rafts were deployed on May 15 (MDN) and June 1 (MDL). The 2012 simulations in this study ran from April 17 through June 30 , so a spatially uniform wind forcing based on data collected at a Bureau of Reclamation Agrimet station (AGKO, fig. 1) was used between April 17 and May 15, followed by a spatially uniform wind forcing based on data from MDN that was used until June 1, followed by a spatial interpolation of data from both MDN and MDL that was used through the rest of the simulation.

\section{Particle Tracking}

Particles were inserted into the model domain at two locations representing larvae entering the lake at the Williamson River boundary from spawning areas upstream, and larvae entering the lake at the eastern shoreline springs where spawning also occurs. Particles representing larvae from the river were inserted into the model along a transect across the Williamson River channel, about $175 \mathrm{~m}$ upstream of the point where the channel enters the river delta (fig. 1), as described in Wood and others (2014). Particles representing larvae swimming up from the gravel at the shoreline springs were distributed equally along four 30-m transects centered on the four major shoreline springs (fig. 1). Simulations started in mid-April and continued through the end of June in each year. Particles were inserted into the hydrodynamic simulation over the course of the 70-day simulation in proportion to the total count of sucker larvae in the drift at Modoc Point Road bridge and the total count of sucker larvae from the springs, as reconstructed using the method described in "Larval Drift Boundary Conditions". Over the course of the entire simulation, 8,540, 1,017, and 3,758 particles representing Lost River larvae from river spawning areas, Lost River larvae from shoreline spawning areas, and shortnose larvae from river spawning areas, respectively, were inserted into the model domain in $2011 ; 7,447,930$, and 3,491 particles representing Lost River larvae from river spawning areas, Lost River larvae from shoreline spawning areas, and shortnose larvae from river spawning areas, respectively, were inserted into the model domain in 2012.

Details of the particle-tracking algorithm are provided in Wood and others (2014); the most salient points are summarized here. The depthaveraged velocities supplied by the hydrodynamic model at each time step were modified by adding a random component before being used to transport particles. The random component comprised two additive parts: one part simulated passive dispersal by turbulent eddies, and the second part simulated active dispersal by swimming. The first part was proportional to the eddy dispersion coefficient, and the second part was proportional to an age-dependent swim speed (3.5 body lengths per second). The age of the particle in days was converted to length using a length-atage linear regression $\left(\mathrm{R}^{2}=0.77\right)$ obtained from aging larvae of both Lost River and shortnose suckers (112 total) between 10 and $19 \mathrm{~mm}$ in standard length (total length minus tail length) that were collected in the Williamson River Delta in 2009 (Erdman and Hendrixson, 2010), following the methods of Terwilliger and others (2003). An additional simulated behavior incorporated the observation from measurements made in the river that sucker larvae swim up from the gravel and drift only at night (Ellsworth and Martin, 2012). For that reason, particles in the part of the model domain representing the submerged channel of the Williamson River through the delta were held in place from sunrise to sunset during each day, and then tracking of these particles resumed at sunset. As in Wood and others (2014), mortality was applied to the particles as a postprocessing step, at a rate of 0.051 per day. To simulate mortality at this rate, $5 \%$ of the particles in the domain at midnight on each simulation day were selected randomly and deleted from that time forward. The process was repeated for each simulation day. 


\section{Comparison of Particle-Tracking Results to Field Data}

Daytime field samples were collected with a trawl $\left(0.8 \times 1.5-\mathrm{m}\right.$ opening with a $2.5-\mathrm{m} \mathrm{Nitex}{ }^{\circledR}$ net of $1,000-\mu \mathrm{m}$ bar mesh mounted on an aluminum frame with runners [Simon and others, 2013]). Fish were identified and measured, fixed in $10 \%$ formalin, and later transferred to $50 \%$ isopropanol for long-term storage. Samples were collected at two types of sites on different weeks: long term index sites (once each in 2011 and 2012) and sites based on a spatially balanced design (twice each in 2011 and 2012). Only the data from the spatially balanced design were used in this study because the purpose was to compare model results to field data collected throughout the open waters of the lake, and the index sites were fewer and located primarily at the shoreline.

Two systemwide spatially balanced surveys were conducted. In 2011, the first survey took place over 5 days between May 23 and May 27 and did not include the northwest part of the lake west of a line from Eagle Ridge. The second survey took place during June 20-23, and included all of Upper Klamath and Agency Lakes (Simon and others, 2013). In 2012, the surveys took place between June 11 and June 15, and between June 25 and June 28; both surveys included all of Upper Klamath and Agency Lakes (Simon and others, 2013). Sampling used a larval trawl and was designed to sample the upper $0.8 \mathrm{~m}$ of Upper Klamath and Agency Lakes in a way that gave every point in a substratum an equal probability of being sampled. The Upper Klamath and Agency Lakes system was divided into five zones (Agency Lake —zone 0, the Williamson River Delta - zone 1, northwestern bays-zone 2, midlake, Bare Island to Buck Island-zone 3, and the southern lake south of Buck Island-zone 4). Onshore samples were taken either from shore or, rarely, from the boat. When setting from shore, a single net was set at a maximum depth of $0.8 \mathrm{~m}$ (range $0.3-0.8 \mathrm{~m}$ ) or a maximum distance of $9 \mathrm{~m}$ (range 2-9 $\mathrm{m}$ ) from shore, depending on which came first, and pulled to shore after 2 minutes.
When shoreline substrate or access made setting from shore impossible, onshore samples were taken from the boat. For these sites, a single larval trawl was set by dropping it from the front of the boat, motoring in reverse for $13 \mathrm{~m}$ (either to shore or parallel to shore), and pulling the net to the boat after 2 minutes. For nearshore and offshore samples, two larval trawls were towed for 1 minute, one on each side of the boat, with the cod-end open on the port side and closed on the starboard side. Both trawls were set with the upper frame of the net within $2 \mathrm{~cm}$ of the surface. The available effort then was allocated to a total number of transects and total number of samples for each lake, based on horizontal grid lines 100 $\mathrm{m}$ apart, and a random determination of the starting transect and starting distance from shore. Sample volume at nearshore and offshore sites was measured with a calibrated mechanical velocimeter, with a mechanism to prevent back flow. At onshore sites, a wedge of water that tapered to shore was sampled, and the volume sampled was estimated from field measurements (depth at start, depth at end, distance, and net width). Density estimates for net catches were based on these sampled volumes. More details on how the larval trawl samples were collected are provided in Simon and others (2013).

Comparison of model results with field data was largely qualitative. The spatial patterns of fish density were compared on the basis of maps of particles and larval trawl densities. The temporal progression of fish density was compared across zones on the basis of a zone-specific Catch per Unit Effort (CPUE). Daily zone-specific CPUE for tracked particles was defined as the total number of particles in a zone at 12:00 p.m. on a given day, divided by the volume of water in that zone. The zone-specific CPUE of larval trawls on a survey date was defined as the total number of fish caught in a zone, divided by the total volume of water sampled by all the nets that were set. The survey date was taken to be the midpoint of all the days required to complete the survey, and all nets set during the survey dates were combined to create the CPUE. For example, 
June 13, 2011, was the survey date for the June 11-15, 2011, survey, and all nets set in all zones during those 5 days were combined to create the zone-specific CPUE for the June 13 survey.

To further compare the simulations to field data, particle ages were converted to fish lengths using the length-at-age regression. For larvae entering the lake from the Williamson River, particle age was calculated by adding the number of days the particle had been in the simulation to 9.3 days (the age assigned to larvae entering the model domain), on the assumption that larvae emerged from gravel at 8.3 days (the age of the median-sized fish in the drift at the Modoc Point Road bridge, based on the length-at-age regression) and then spent 1 day traveling down the river from the Modoc Point Road bridge to the point of insertion into the model (Wood and others, 2014). Larvae entering the lake from the springs were assigned an age of 8.3 days (emerging from the gravel at the same age as the river larvae, but without the 1-day travel time). The progression of lengths through time was compared across zones with the use of boxplots and zone-specific median lengths. The length of tracked particles was compared quantitatively to the length of larval trawl catches across time and zones together by pairing the lengths of fish captured in individual nets at field sites with the lengths determined from particle tracking at the same site at the same time, and calculating a rank order correlation coefficient (Spearman $\rho$ ). Consistent with Wood and others (2014), particles within a $150-\mathrm{m}$ radius of a field site, in a time window of 3 hours surrounding the net set time were identified and their median age calculated. This radius and time window was consistent with Wood and others (2014), and was a compromise between precision in sampling time and location (particle locations are saved every hour and a single $\mathrm{x}-\mathrm{y}$ coordinate would not necessarily correspond to any particles) and the need to obtain a valid length distribution while avoiding duplicate particles. For all fish and separately for each species, the median age was converted to a median length using the same length-at-age regression.

\section{Sensitivity of Particle Retention to Wind, River Discharge, and Lake Elevation}

In order to determine the sensitivity of particle retention to meteorological forcing and hydrodynamics, a series of numerical "experiments" was completed that encompassed a matrix of wind, river discharge, and lake elevation conditions. Each of the three independent variables was varied through a series of simulations while the other two were held constant. The particles in each simulation were released simultaneously so that each particle experienced the same history of forcing functions and boundary conditions, with only the random effects of dispersal causing each particle to follow a different trajectory and therefore experience a slightly different history of water currents between its insertion into the model domain and the end of the simulation or the exit of the particle, whichever came first.

\section{Wind Scenarios}

The most difficult boundary condition to deal with when designing "controlled" numerical experiments like the particle retention experiments is wind forcing because it must be realistic in the sense of having both realistic diel fluctuations (particularly in wind speed) and a realistic distribution of wind direction. For this reason, it is not possible to design good experiments that simply hold the wind constant for the duration of the simulation. We opted instead to use several wind forcing scenarios using data that were collected during 2009 when the number of wind collection sites around the lake was at its peak, so detail in the spatial coverage was good. By choosing several historical wind scenarios, a range of conditions could be simulated. In each scenario, the wind forcing at the surface of the lake was obtained from a spatial interpolation of 10-minute data collected at as many as six meteorological stations (fig. 1) in 2009. Simulations of particle groups released at the shoreline springs (designated S1, S2, and S3) used scenarios measured during April 2009, before the rafts were deployed on the lake, and used spatially interpolated data 
from the four land-based stations. Simulations of particles released in the river (groups R1, R2, and R3) used scenarios measured during May and June 2009. Because of the timing of deployment of the floating raft-based meteorological stations, four land-based stations were used to generate one wind-forcing scenario (for R1), four landbased stations and one floating station were used to generate another (for R2), and four land-based stations and two floating stations were used to generate the last (for R3).

To put the wind scenarios used for the model simulations into context, selected characteristics of the wind at one station-WRW-MET located at the Williamson River Delta_-are provided for the period of record in table 1 and figure 2, extracting the data by month, for March through
July. Overall, wind speeds decrease through these months. The high winds in March are often from the south-southeast, but from April through July the wind direction is primarily from the west. Adult females are detected at shoreline springs in March through May, but the largest numbers are detected in April and therefore larvae are expected to emerge from these spawning areas in the largest numbers in April (Martin and others, 2013). Adult fish generally travel up the tributaries to spawn later by about a month, although the timing is influenced by temperature. Larvae are expected to emerge from spawning areas in the Williamson and Sprague Rivers in the largest numbers in May, but larval drift continues well into June (Ellsworth and others, 2012).

Table 1. Selected characteristics of wind data collected at U.S. Geological Survey meteorological station 422807121572500, Williamson River West, Oregon, April 2008-June 2011.

[Period of record $=$ April 2008-June 2011; (S1), etc. = scenarios for the particle groups]

\begin{tabular}{|c|c|c|c|c|c|c|c|c|c|c|c|}
\hline Year & Dates & $\begin{array}{l}\text { Mean } \\
\text { speed } \\
(\mathrm{m} / \mathrm{s})\end{array}$ & $\begin{array}{c}\text { Peak } \\
\text { frequency } \\
(\%)\end{array}$ & $\begin{array}{c}\text { Peak } \\
\text { direction }\end{array}$ & $\begin{array}{c}\text { Frequency } \\
\text { calm } \\
(\%)\end{array}$ & $\begin{array}{c}\text { Frequency } \\
6-8 \mathrm{~m} / \mathrm{s} \\
(\%)\end{array}$ & $\begin{array}{c}\text { Peak } \\
\text { direction } \\
6-8 \mathrm{~m} / \mathrm{s}\end{array}$ & $\begin{array}{c}\text { Frequency } \\
8-10 \mathrm{~m} / \mathrm{s} \\
(\%)\end{array}$ & $\begin{array}{c}\text { Peak } \\
\text { direction } \\
8-10 \mathrm{~m} / \mathrm{s} \\
\end{array}$ & $\begin{array}{c}\text { Frequency } \\
>10 \mathrm{~m} / \mathrm{s} \\
(\%)\end{array}$ & $\begin{array}{c}\text { Peak } \\
\text { direction } \\
>10 \mathrm{~m} / \mathrm{s}\end{array}$ \\
\hline $\begin{array}{l}\text { Period of } \\
\text { Record }\end{array}$ & March & 4.45 & 19.10 & SSE & 2.02 & 17.26 & SSE & 8.14 & SSE & 2.26 & SSE \\
\hline $\begin{array}{l}\text { Period of } \\
\text { Record }\end{array}$ & April & 4.28 & 22.21 & W & 1.24 & 17.20 & W & 5.90 & W & 1.18 & W \\
\hline $\begin{array}{l}\text { Period of } \\
\text { Record }\end{array}$ & May & 3.78 & 17.32 & W & 1.43 & 13.71 & W & 3.48 & WNW & 0.32 & SSE \\
\hline $\begin{array}{l}\text { Period of } \\
\text { Record }\end{array}$ & June & 3.26 & 19.40 & W & 2.05 & 8.68 & W & 1.48 & W & 0.07 & NW \\
\hline $\begin{array}{l}\text { Period of } \\
\text { Record }\end{array}$ & July & 2.49 & 17.42 & W & 2.83 & 2.39 & W & 0.15 & W & 0 & - \\
\hline $\begin{array}{l}2009 \\
(\mathrm{~S} 1)\end{array}$ & April 5-19 & 3.91 & 21.91 & W & 1.39 & 15.12 & W & 3.74 & NW & 0.55 & NNW \\
\hline $\begin{array}{l}2009 \\
(\mathrm{~S} 2)\end{array}$ & April 10-24 & 3.99 & 19.14 & NW & 1.39 & 15.12 & NW & 4.58 & NW & 0.55 & NNW \\
\hline $\begin{array}{l}2009 \\
(\mathrm{~S} 3)\end{array}$ & April 15-29 & 3.85 & 20.39 & NW & 1.66 & 17.48 & W & 3.05 & NW & 0 & - \\
\hline $\begin{array}{l}2009 \\
\text { (R1) }\end{array}$ & May 1-25 & 3.99 & 22.06 & W & 1.25 & 16.57 & W & 3.75 & SSE & 0.25 & SSE \\
\hline $\begin{array}{l}2009 \\
\text { (R2) }\end{array}$ & $\begin{array}{l}\text { May 15- } \\
\text { June } 8\end{array}$ & 3.24 & 14.74 & NW & 2.08 & 7.58 & W & 1.17 & WSW & 0.08 & SE \\
\hline $\begin{array}{l}2009 \\
\text { (R3) }\end{array}$ & June $1-25$ & 2.98 & 20.68 & W & 2.84 & 4.17 & W & 1.17 & W & 0 & - \\
\hline
\end{tabular}



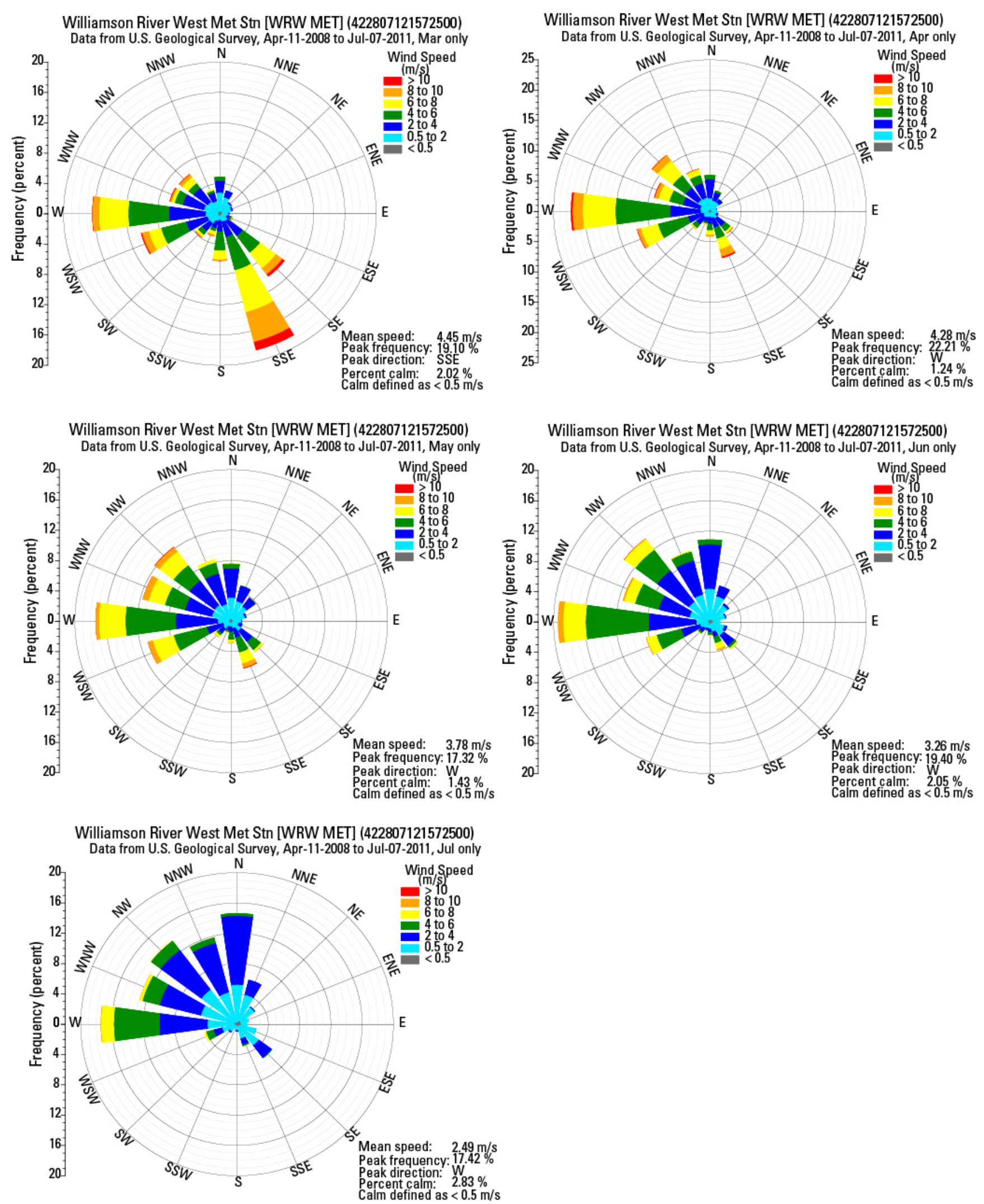

Figure 2. Monthly wind roses from site Williamson River West (WRW-MET, U.S. Geological Survey station 422807121572500), Upper Klamath Lake, Oregon, April 2008-June 2011. 
The three wind scenarios used to run simulations of particle release from the spawning areas located at springs on the eastern shoreline of the lake were all segments of the record collected in April 2009 (table 1, fig. 3). The wind scenario associated with group S1 was characterized primarily by moderate (4-8 meters per second $[\mathrm{m} / \mathrm{s}]$ ) westerly winds, and secondarily by northwesterly winds in the $8-10 \mathrm{~m} / \mathrm{s}$ category (table 1). The wind scenario associated with group S2 was characterized by moderate $(4-8 \mathrm{~m} / \mathrm{s})$ and strong $(8-10 \mathrm{~m} / \mathrm{s})$ northwesterly winds. The wind scenario associated with group S3 was characterized primarily by moderate $(4-8 \mathrm{~m} / \mathrm{s})$ winds from the northwest and west, and, secondarily, by strong $(8-10 \mathrm{~m} / \mathrm{s})$ northwesterlies. The use of three wind-forcing scenarios provides important variability for the sensitivity analysis, but in general, the $\mathrm{S} 1$ scenario is most representative of the "average" April conditions at this site, based on the peak direction, which is from the west in both the 4-6 and 6$8 \mathrm{~m} / \mathrm{s}$ category; the peak direction of the other two springs wind-forcing scenarios $\mathrm{S} 2$ and $\mathrm{S} 3$ is rotated to the northwest (table 1). The mean speed of $3.92 \mathrm{~m} / \mathrm{s}$ is lower but comparable to $4.28 \mathrm{~m} / \mathrm{s}$ for the period of record.
Williamson River West Met Stn [WRW MET] (422807121572500) Data from U.S. Geological Survey, Apr-05-2009 to Apr-19-2009
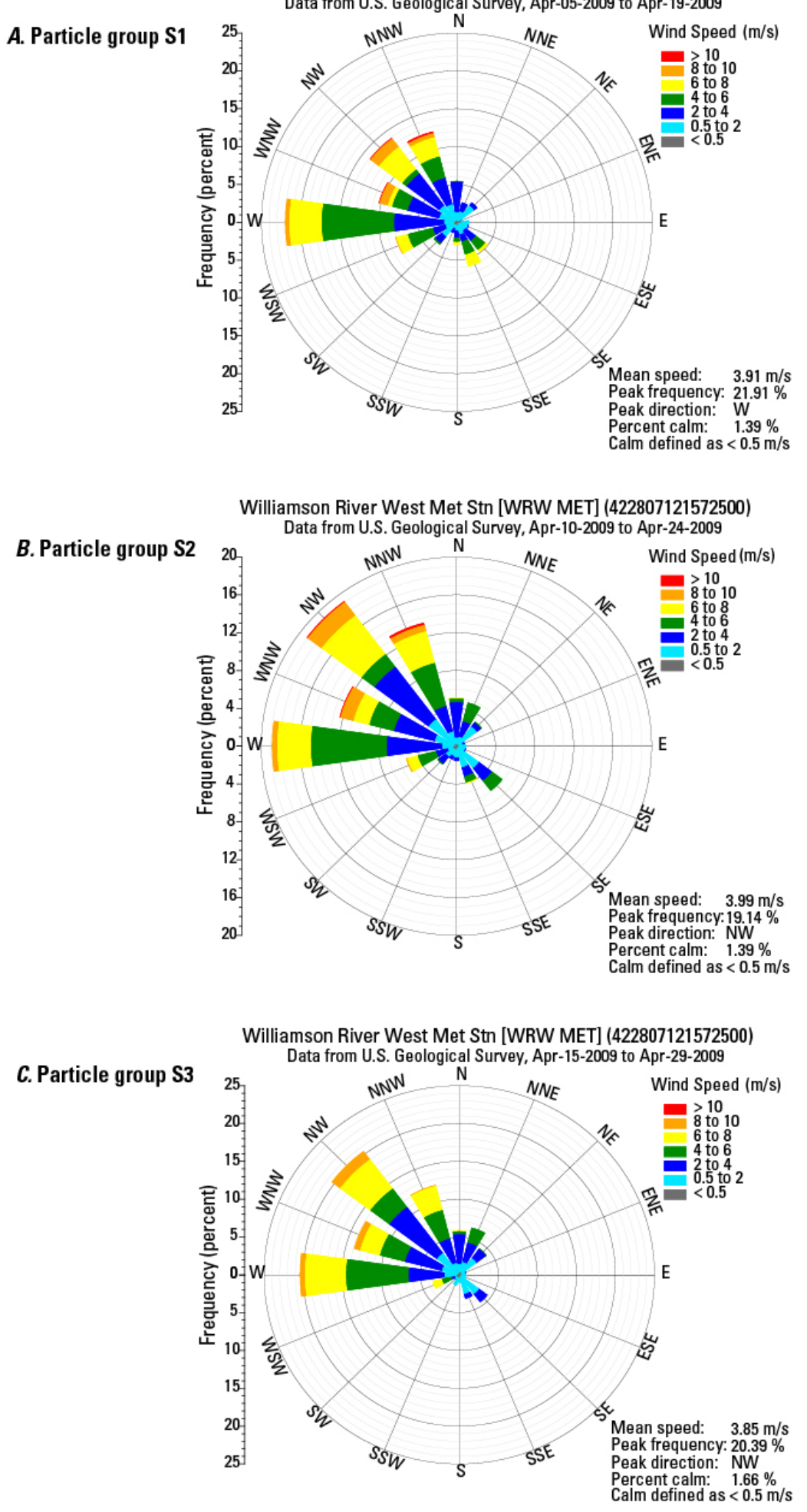

Figure 3. Wind roses from site Williamson River West (WRW-MET, U.S. Geological Survey station 422807121572500), Upper Klamath Lake, Oregon, for 15-day segments corresponding to wind scenarios for release of particles from spawning grounds at eastern shoreline springs. 
The three wind scenarios used to run simulations of particle release from the spawning areas in the Williamson River were segments of record collected during May and June 2009 (table 1, fig. 4). The wind scenario associated with group R1 was characterized primarily by moderate ( $4-8$ meters per second $[\mathrm{m} / \mathrm{s}])$ westerlies, although there were short periods of strong winds ( 8 to $>10 \mathrm{~m} / \mathrm{s}$ ) from the south-southeast. The wind scenario associated with group R2 was characterized primarily by light winds $(2-4 \mathrm{~m} / \mathrm{s})$ from the north and northwest, and, secondarily, by moderate winds $(6-8 \mathrm{~m} / \mathrm{s})$ from the west, with short periods of strong winds $(8-10$ $\mathrm{m} / \mathrm{s}$ ) from the west-southwest. The wind scenario associated with group R3 was characterized primarily by moderate $(4-8 \mathrm{~m} / \mathrm{s})$ and, secondarily, by strong $(8-10 \mathrm{~m} / \mathrm{s})$ westerly winds. The use of three wind-forcing scenarios again provides important variability for the sensitivity analysis, but in general, the $\mathrm{R} 1$ scenario is most representative of the "average" May conditions at this site, based on a mean speed of $3.99 \mathrm{~m} / \mathrm{s}$ (compared to $3.78 \mathrm{~m} / \mathrm{s}$ for the period of record; table 1) and the peak direction, which is from the west. This scenario also includes a wind reversal from the south-southeast, which is incorporated into the average May conditions. The $\mathrm{R} 2$ scenario is most representative of June conditions based on a mean speed of $3.24 \mathrm{~m} / \mathrm{s}$ (compared to $3.26 \mathrm{~m} / \mathrm{s}$ for the period of record), although the peak direction is rotated slightly to the northwest (table 1).
Williamson River West Met Stn [WRW MET] (422807121572500)

A. Particle group $\mathbf{R} 1$
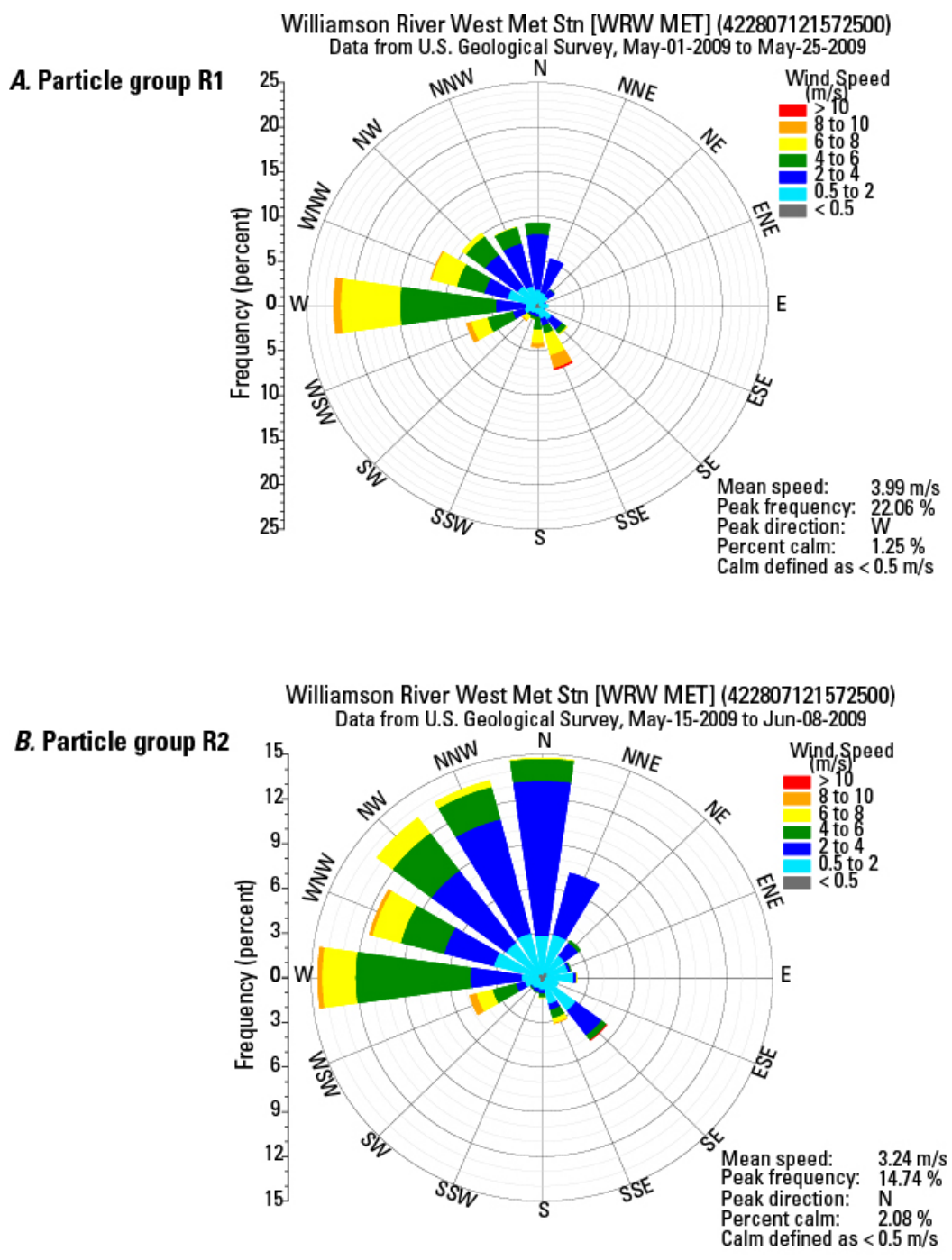

C. Particle group R3

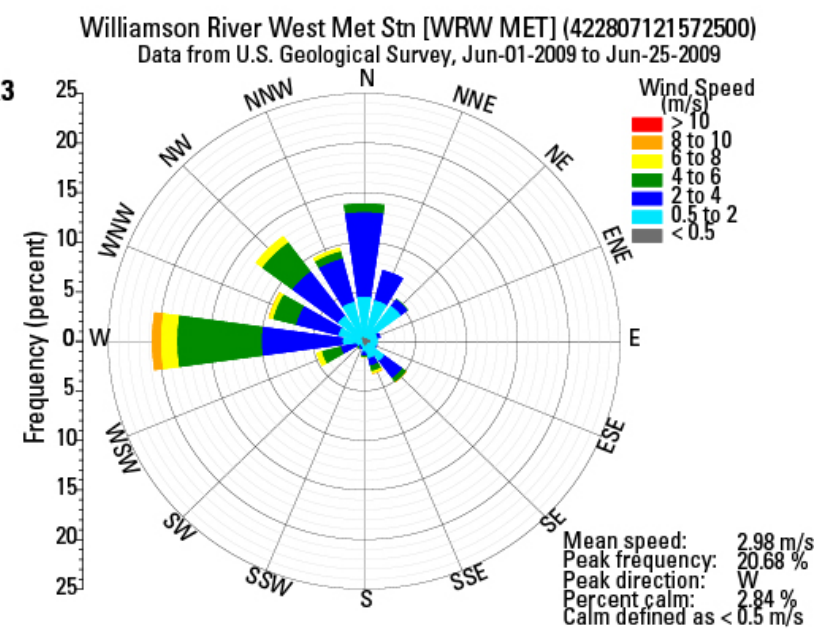

Figure 4. Wind roses at site Williamson River West (WRW-MET, U.S. Geological Survey station 422807121572500), Oregon, for 25-day segments corresponding to wind scenarios for release of particles from spawning grounds in the Williamson and Sprague Rivers. 
Williamson River Discharge and Lake Elevation

During each particle-retention simulation, two tributary inflows and the Upper Klamath Lake outflow were held at constant values. Four Williamson River discharge values $(20,50,75$, and $100 \mathrm{~m}^{3} / \mathrm{s}$ ) were used. These values spanned all but the lowest $5 \%$ of the distribution of March monthly mean values, and the upper $50 \%$ of the distribution of June monthly mean values (table 1). The second inflow at the Wood River was set to 0.56 times the Williamson River inflow because this was the average value of the ratio of the Wood River inflow to Williamson River inflow during May-June 2004 and 2005, based on gaged flows in the Wood River basin (Graham Matthews and Associates, 2009). The sum of the outflows from the lake (Link River and A-canal) was set to the sum of the inflows in order to keep the lake elevation constant during the simulation. Four values of lake elevation were used, spanning the entire range of monthly mean lake elevations observed historically (table 1): 4,140.5, 4,141.5, 4,142.5, and 4,143.3 ft.
Given that lake elevation and river discharge were both held constant, these scenarios were not designed to determine the sensitivity of particle retention to the rate at which the lake might be filling or draining. During March and April, the lake normally is filling and the lake elevation normally is increasing at a rate between about 0.1 and 0.33 meter per month (approximate 10th and 90th percentiles of the change in monthly mean lake stage, table 2). In May and June, the lake either can be filling or draining, depending on conditions and management; June lake elevation often decreases between about 0.1 and 0.25 meter per month (approximate 10th and 50th percentiles, table 2). It was beyond the scope of this study to investigate sensitivity of particle retention to filling or draining lake conditions; note, however, that the assumptions of constant lake elevation are unlikely to be met in Upper Klamath Lake over the course of 25 days during the period from March to June.

Table 2. Selected percentiles of monthly mean discharge data for the Williamson River (U.S. Geological Survey station 11502500) and stage data for Upper Klamath Lake (U.S. Geological Survey station 11507001), Oregon, March-June 1975-2012 $\left[\mathrm{ft}^{3} / \mathrm{s}=\right.$ cubic feet per second; $\mathrm{m}^{3} / \mathrm{s}=$ cubic meters per second]

\begin{tabular}{|c|c|c|c|c|c|c|c|c|}
\hline \multicolumn{9}{|c|}{ Williamson River monthly mean discharge } \\
\hline \multirow[b]{2}{*}{ Percentile } & \multicolumn{2}{|c|}{ March } & \multicolumn{2}{|c|}{ April } & \multicolumn{2}{|c|}{ May } & \multicolumn{2}{|c|}{ June } \\
\hline & $\mathrm{ft}^{3} / \mathrm{s}$ & $\mathrm{m}^{3} / \mathrm{s}$ & $\mathrm{ft}^{3} / \mathrm{s}$ & $\mathrm{m}^{3} / \mathrm{s}$ & $\mathrm{ft}^{3} / \mathrm{s}$ & $\mathrm{m}^{3} / \mathrm{s}$ & $\mathrm{ft}^{3} / \mathrm{s}$ & $\mathrm{m}^{3} / \mathrm{s}$ \\
\hline 99 & 3,691 & 104.5 & 3,318 & 94.0 & 3,036 & 86.0 & 2,431 & 68.8 \\
\hline 95 & 3,213 & 91.0 & 3,181 & 90.1 & 2,992 & 84.7 & 2,001 & 56.7 \\
\hline 90 & 2,944 & 83.4 & 3,036 & 86.0 & 2,864 & 81.1 & 1,768 & 50.1 \\
\hline 75 & 1,993 & 56.4 & 2,228 & 63.1 & 2,026 & 57.4 & 1,155 & 32.7 \\
\hline 50 & 1,496 & 42.4 & 1,662 & 47.1 & 1,497 & 42.4 & 802 & 22.7 \\
\hline 25 & 1,103 & 31.2 & 1,039 & 29.4 & 940 & 26.6 & 573 & 16.2 \\
\hline 10 & 815 & 23.1 & 834 & 23.6 & 737 & 20.9 & 503 & 14.2 \\
\hline 5 & 732 & 20.7 & 701 & 19.9 & 540 & 15.3 & 395 & 11.2 \\
\hline 1 & 619 & 17.5 & 583 & 16.5 & 391 & 11.1 & 338 & 9.6 \\
\hline
\end{tabular}

Table continued on next page. 
Table 2. Selected percentiles of monthly mean discharge data for the Williamson River (U.S. Geological Survey station 11502500) and stage data for Upper Klamath Lake (U.S. Geological Survey station 11507001), Oregon, March-June 1975-2012-continued

$\left[\mathrm{ft}^{3} / \mathrm{s}=\right.$ cubic feet per second; $\mathrm{m}^{3} / \mathrm{s}=$ cubic meters per second]

\begin{tabular}{|c|c|c|c|c|c|c|c|c|}
\hline \multicolumn{9}{|c|}{ Upper Klamath Lake monthly mean lake stage } \\
\hline & \multicolumn{2}{|c|}{ March } & \multicolumn{2}{|c|}{ April } & \multicolumn{2}{|c|}{ May } & \multicolumn{2}{|c|}{ June } \\
\hline Percentile & feet & meters & feet & meters & feet & meters & feet & meters \\
\hline 99 & $4,142.86$ & $1,262.7$ & $4,143.18$ & $1,262.8$ & $4,143.30$ & $1,262.9$ & $4,143.15$ & $1,262.8$ \\
\hline 95 & $4,142.68$ & $1,262.7$ & $4,143.12$ & $1,262.8$ & $4,143.24$ & $1,262.9$ & $4,143.13$ & $1,262.8$ \\
\hline 90 & $4,142.62$ & $1,262.7$ & $4,143.07$ & $1,262.8$ & $4,143.16$ & $1,262.8$ & $4,143.09$ & $1,262.8$ \\
\hline 75 & $4,142.46$ & $1,262.6$ & $4,142.91$ & $1,262.8$ & $4,143.02$ & $1,262.8$ & $4,142.92$ & $1,262.8$ \\
\hline 50 & $4,142.24$ & $1,262.6$ & $4,142.74$ & $1,262.7$ & $4,142.96$ & $1,262.8$ & $4,142.63$ & $1,262.7$ \\
\hline 25 & $4,142.05$ & $1,262.5$ & $4,142.45$ & $1,262.6$ & $4,142.62$ & $1,262.7$ & $4,142.10$ & $1,262.5$ \\
\hline 10 & $4,141.49$ & $1,262.3$ & $4,141.97$ & $1,262.5$ & $4,142.27$ & $1,262.6$ & $4,141.84$ & $1,262.4$ \\
\hline 5 & $4,141.12$ & $1,262.2$ & $4,141.76$ & $1,262.4$ & $4,141.25$ & $1,262.3$ & $4,141.45$ & $1,262.3$ \\
\hline 1 & $4,140.23$ & $1,261.9$ & $4,140.75$ & $1,262.1$ & $4,141.18$ & $1,262.2$ & $4,140.02$ & $1,261.9$ \\
\hline \multicolumn{9}{|c|}{ Upper Klamath Lake change in monthly mean lake stage from previous month } \\
\hline & \multicolumn{2}{|c|}{ March } & \multicolumn{2}{|c|}{ April } & \multicolumn{2}{|c|}{ May } & \multicolumn{2}{|c|}{ June } \\
\hline Percentile & feet & meters & feet & meters & feet & meters & feet & meters \\
\hline 99 & 1.345 & 0.410 & 1.000 & 0.305 & 0.612 & 0.187 & 0.349 & 0.106 \\
\hline 95 & 1.332 & 0.406 & 0.962 & 0.293 & 0.499 & 0.152 & 0.269 & 0.082 \\
\hline 90 & 1.149 & 0.350 & 0.821 & 0.250 & 0.431 & 0.131 & 0.244 & 0.074 \\
\hline 75 & 0.919 & 0.280 & 0.601 & 0.183 & 0.326 & 0.099 & 0.006 & 0.002 \\
\hline 50 & 0.776 & 0.237 & 0.476 & 0.145 & 0.193 & 0.059 & -0.239 & -0.073 \\
\hline 25 & 0.577 & 0.176 & 0.368 & 0.112 & -0.039 & -0.012 & -0.632 & -0.193 \\
\hline 10 & 0.313 & 0.095 & 0.298 & 0.091 & -0.172 & -0.052 & -0.849 & -0.259 \\
\hline 5 & 0.265 & 0.081 & 0.150 & 0.046 & -0.501 & -0.153 & -1.014 & -0.309 \\
\hline 1 & 0.136 & 0.041 & 0.067 & 0.020 & -0.510 & -0.155 & -1.226 & -0.374 \\
\hline
\end{tabular}




\section{Particle-Release Scenarios}

For each of the springs and river-release particle simulations, there were 3 wind scenarios, 4 discharge values, and 4 lake elevation values, for a total of 48 simulations of release at springs and 48 simulations of release in the river. For a springs-release simulation, on day 1 at midnight (after allowing 5 days for the modeled hydrodynamics to come into balance with the forcing functions and boundary conditions), 250 particles were distributed equally along four $30-\mathrm{m}$ transects centered on the four major shoreline springs(fig. 1). For a river-release simulation, on day 1 at midnight (after allowing 5 days for model initialization), 250 particles were distributed equally along a transect across the Williamson River channel, about $175 \mathrm{~m}$ upstream of the point where the channel enters the river delta (fig. 1). These particles were tracked as in the 2011-12 simulations for at least 30 days. Because the purpose of these experiments was to determine the relative retention in and loss from the lake of the particles, no mortality was applied. Retention and loss rates, therefore, are not meaningful as absolute values, and only become meaningful relative to each other when compared among simulations across a matrix of conditions of wind, river discharge, and lake elevation. Applying a mortality term before determining retention and loss rates would make those rates more meaningful aside from these comparisons, but would require many more particles and the simulations would take more computation time. Particles were considered to have exited the domain when their position was within $300 \mathrm{~m}$ of the outlet of the lake, as represented in the model boundary.

Some simulations were repeated in order to investigate the precision in the estimates of particle loss and retention. A few simulations also were repeated with 1,000 particles in order to investigate the precision by comparing estimates based on simulations with 250 particles relative to those with 4 times as many particles.

\section{Results}

\section{Larval Drift Boundary Conditions}

The parameters that minimized the sum of squared errors for LRS and SNS were $\tau$ equal to $2 \%$ of the total female adults migrating that year, and a LOWESS window span of 0.2. Using these values, the final model for the boundary condition simulated the shape and timing of LRS density at the Modoc Point Road bridge moderately well in 3 of the 4 years, but did poorly in 2010 (fig. 5). The average shape of the LRS drift based on the 4 years of data consists of a single large, early pulse of larvae that increases rapidly on the front end but decays more slowly on the back end. In 2010, there were two LRS pulses, the second of which was larger, so that year did not fit the pattern. The average shape of SNS drift based on these 4 years of data consists of three pulses, the first of which is timed almost simultaneously with the LRS pulse, and the second of which is the largest. In 2007, the first SNS pulse was the largest and the next two were small; therefore, that year did not fit the pattern (fig. 6).

The calibrated parameters were used to estimate the larval drift of LRS and SNS larvae at the Modoc Point Road Bridge in 2011 and 2012. LRS larvae at the springs were estimated using the adult counts at the springs (fig. 7). The resulting time series of larvae entering the system in 2011 had peaks of LRS springs larvae on May 6, LRS river larvae on May 27, SNS river larvae on June 12, and secondary peaks of SNS river larvae on May 26 and June 30. The absolute number of larvae entering the system is the same in each year and is not an accurate count; the ratio of LRS river larvae to SNS river larvae and LRS springs larvae, however, is intended to accurately capture the relative contribution of each group to the combined population. In 2012, the return of adults to spawn began a few days later than in 2011, so the peaks of larvae entering the system in the estimated boundary condition also were a few days later. LRS springs larvae peaked on May 11, LRS river larvae on May 31, and SNS river larvae on June 14. 

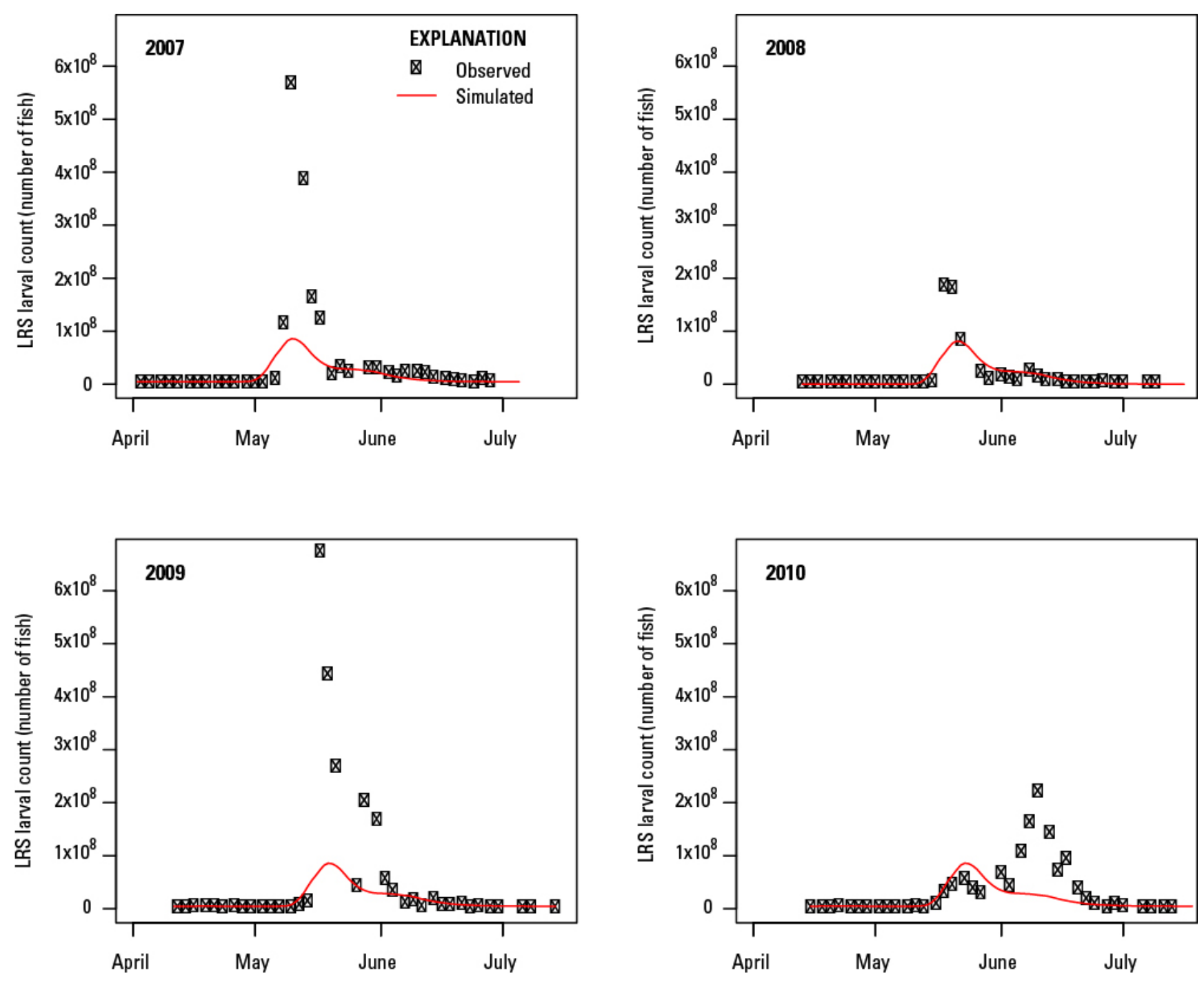

Figure 5. Simulated and observed Lost River larval sucker (LRS) densities at the Modoc Point Road bridge in the Williamson River, Oregon, 2007-2010. 

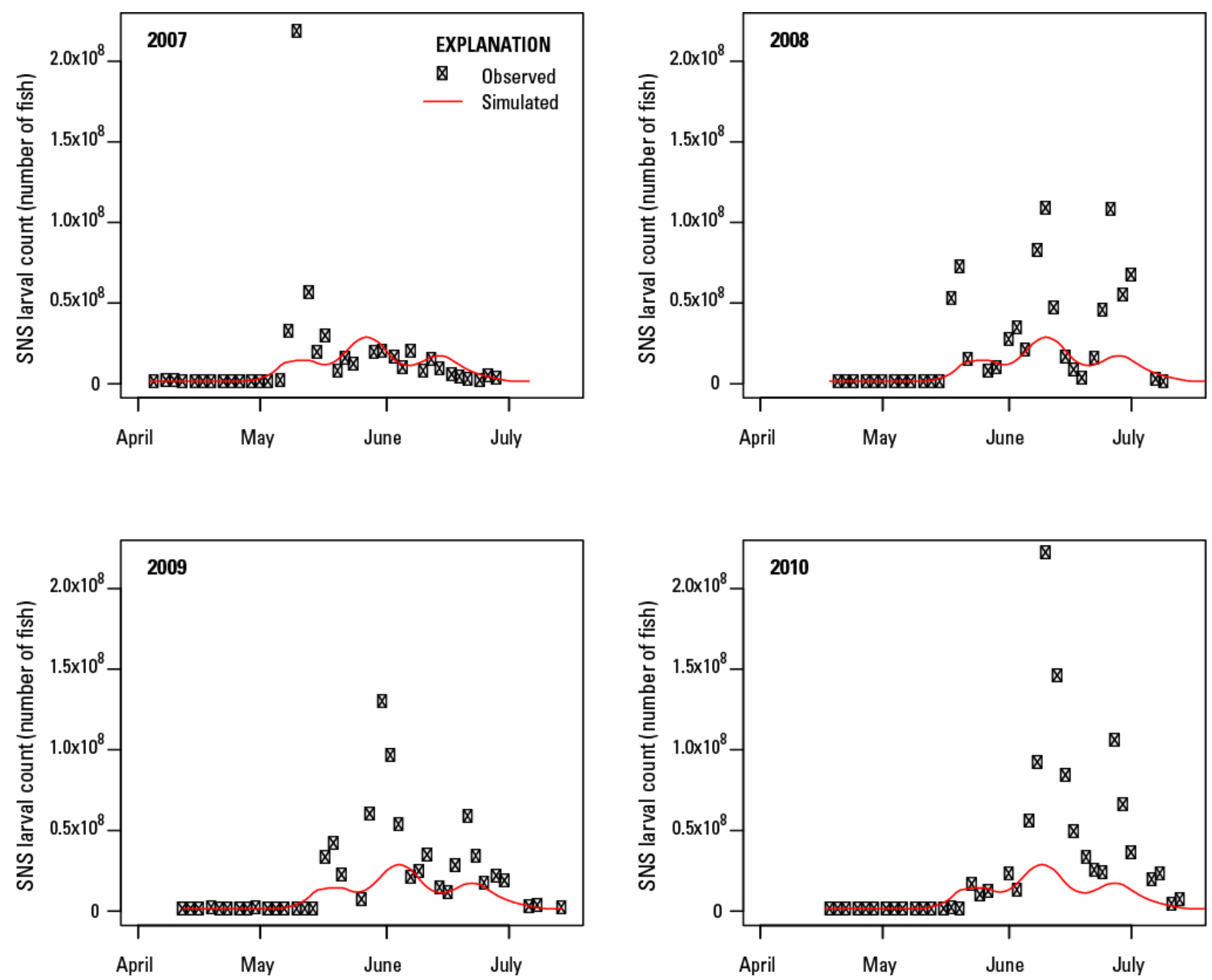

Figure 6. Simulated and observed shortnose larval sucker (SNS) densities at the Modoc Point Road bridge in the Williamson River, Oregon, 2007-2010. 

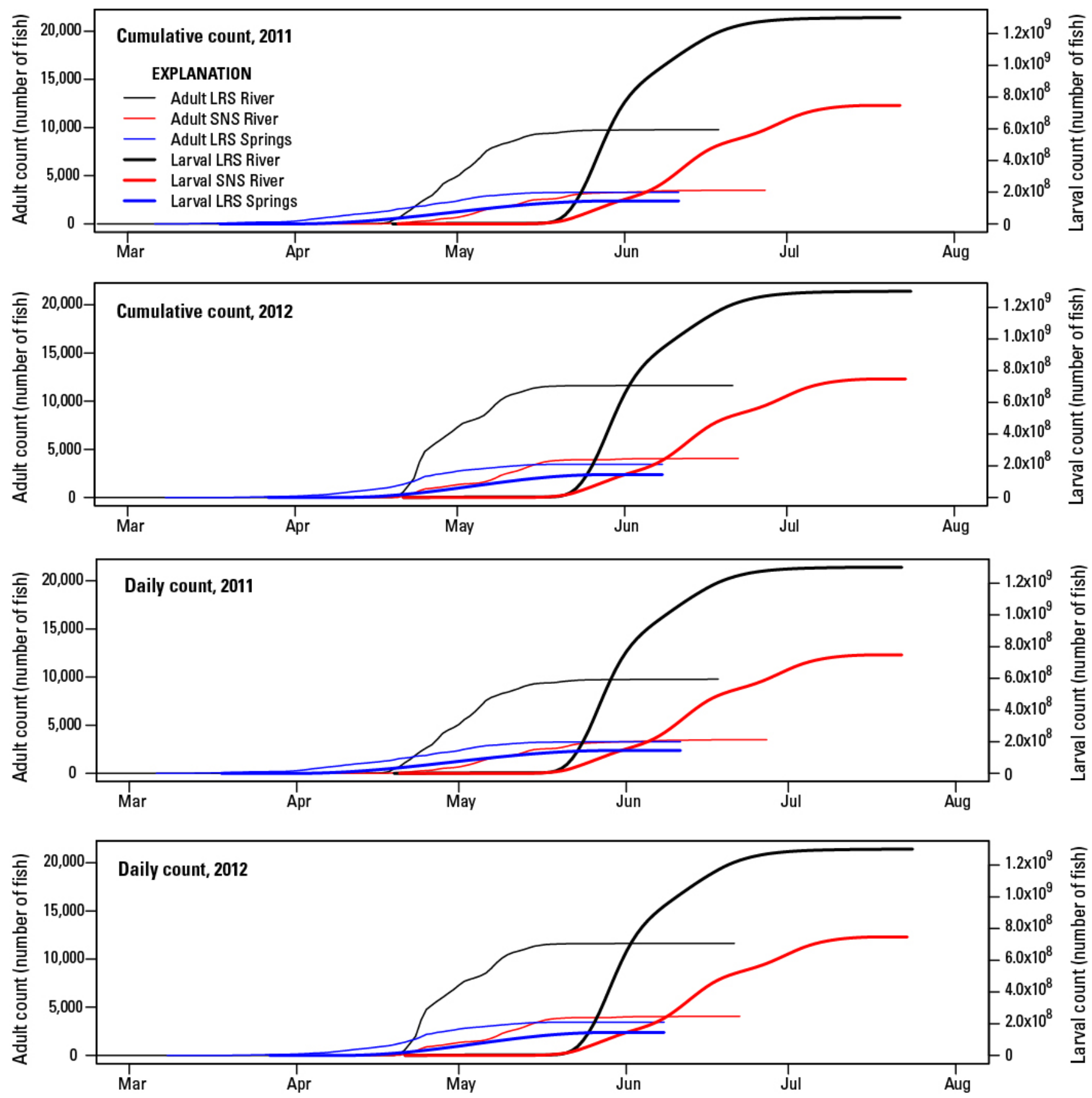

Figure 7. Simulated Lost River sucker (LRS) and shortnose sucker (SNS) larval drift boundary conditions at Modoc Point Road bridge and eastern shoreline springs compared to cumulative and daily adult female fish counts, 201112, Upper Klamath Lake, Oregon.. 


\section{Comparison of Particle-Tracking Results with Net Catches}

The lakewide distribution of larval density as determined by particle tracking was compared qualitatively to the distribution of larval density as determined by trawls. Because each larval trawl survey took place over several days, maps of the spatial distribution of particles at the beginning and end of the 4- or 5-day survey were compared to a map of the spatial distribution of the density in larval trawls over the entire survey (figs. 8 and 9). Some large-scale features of the spatial distribution in the larval trawls appear in the particle distributions, in particular the tendency for fish densities of both species to be higher in the Williamson River Delta, and along the eastern and western shorelines. Other large-scale features of the particle distributions are not seen in the distribution of larvae in the trawls, notably a tendency for fish densities to be high along an east-west pathway between Modoc Rim and the western shoreline north of Howard Bay, which was particularly noticeable during the second survey in 2011 (fig. 8). During the second survey in 2011, the high density of both species also was notable in the larval trawls at the south end of Ball Bay, where particle tracking does not predict high densities. During the second survey of 2012, the density of LRS larvae in trawls was higher in the northern part of the lake than in the southern part; this difference in distribution was not apparent in the particle distribution (fig. 9).

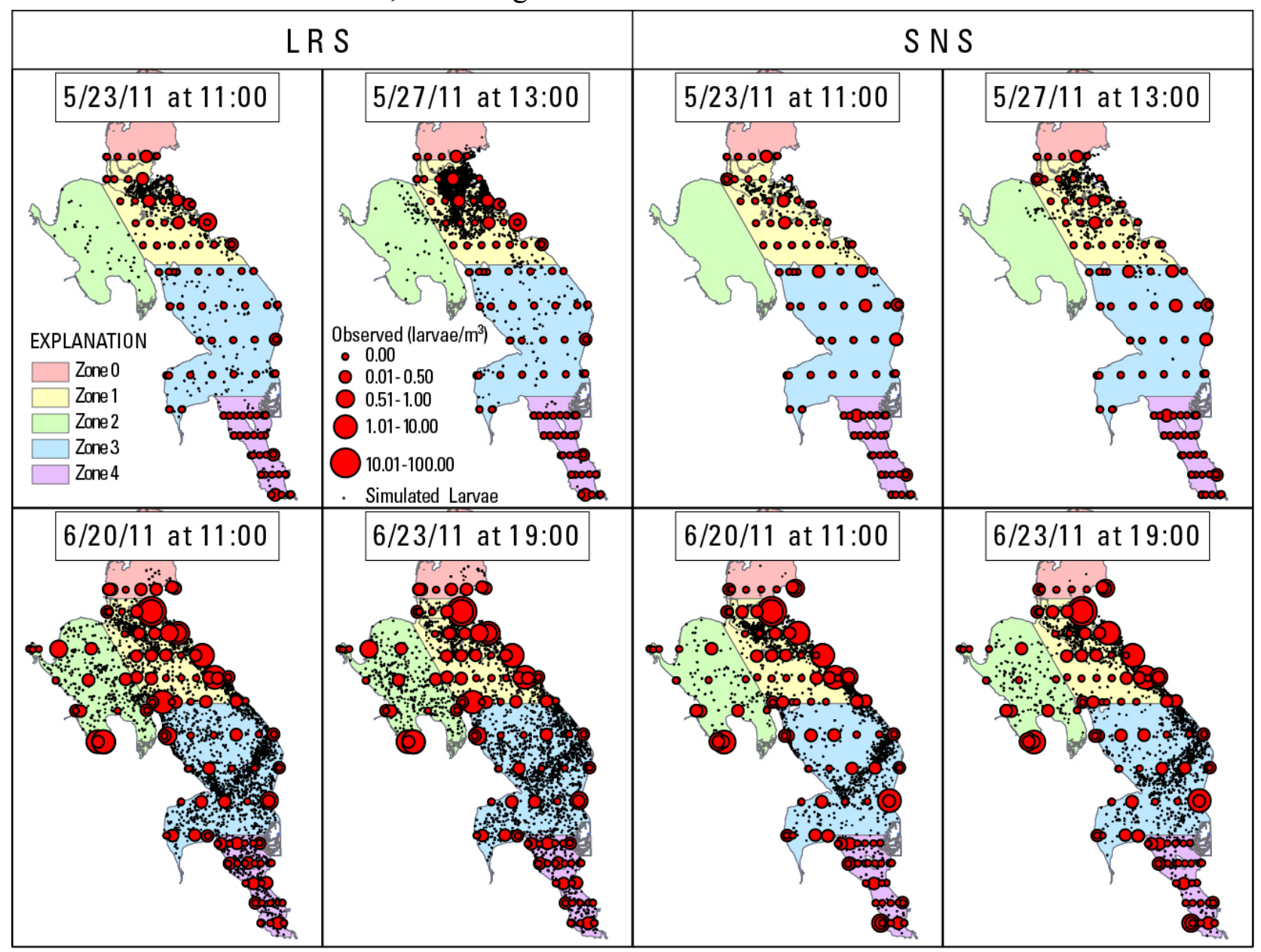

Figure 8. Spatial distribution of particles from the particle-tracking simulation on two dates straddling each of two larval trawl surveys in 2011, and fish density observed in nets during each survey of Lost River (LRS) and shortnose sucker larvae (SNS), Upper Klamath Lake, Oregon. 


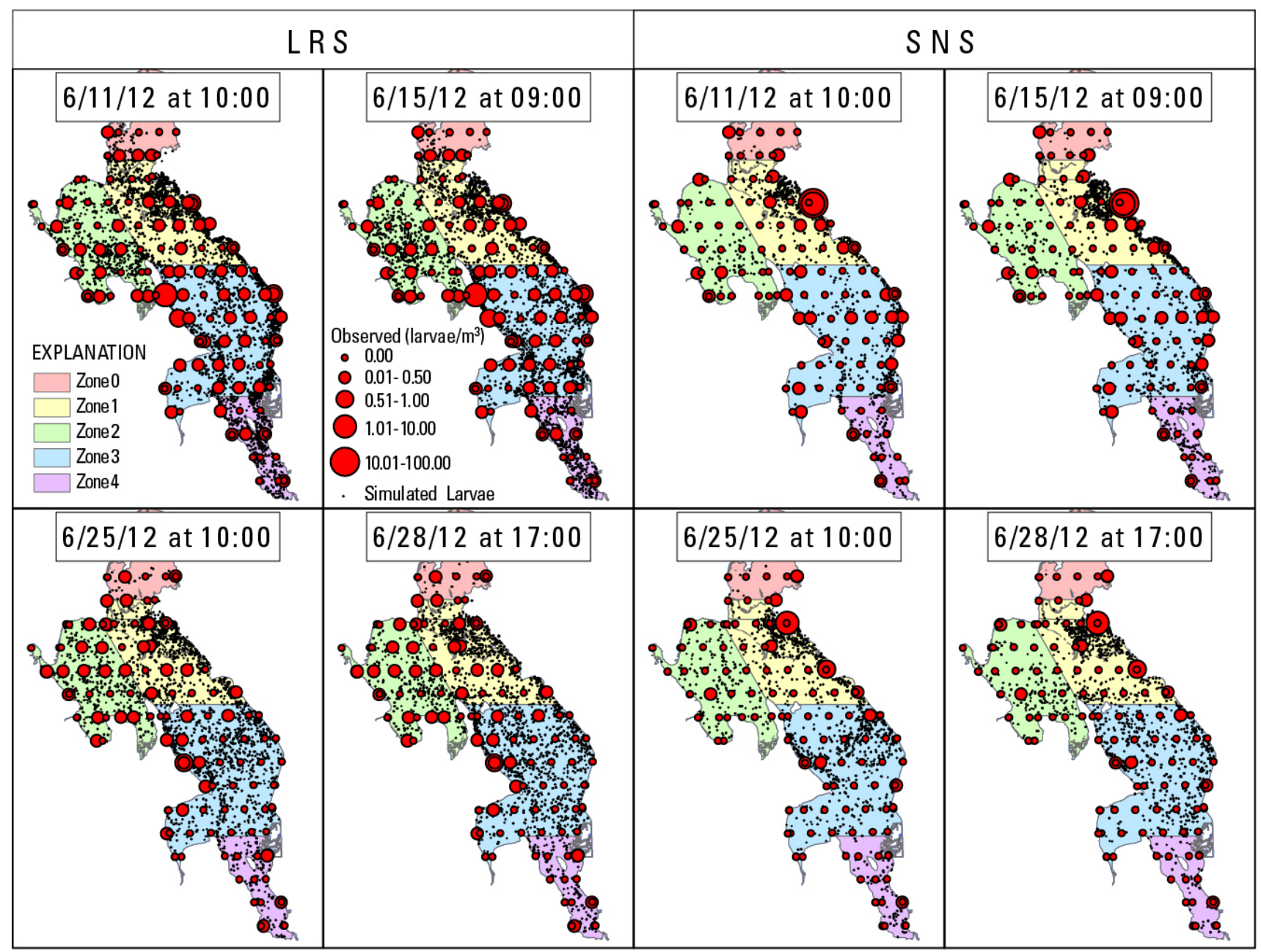

Figure 9. Spatial distribution of particles from the particle-tracking simulation on two dates straddling each of two larval trawl surveys in 2012, and fish density observed in nets during each survey of Lost River (LRS) and shortnose sucker larvae (SNS), Upper Klamath Lake, Oregon.

The particle CPUE in each zone shows the progression in time of larval density simulated by particle tracking. The particle CPUE in each zone can be checked for consistency with the changes in the larval trawl CPUE in each zone between the two sampling surveys in each year (figs. 10, 11). When separated by zone, the CPUE of both species caught in larval trawls increased in every zone between the first (May 25) and second (June 22) surveys in 2011 (fig. 10; table 3). The particle CPUE representing each species in each zone also increased between the two surveys, with the exception of the particle CPUE representing LRS larvae in zone 1 around the Williamson River Delta, which decreased between the two surveys as the first survey occurred on the rising limb of the large pulse of LRS larvae in the reconstructed boundary condition and the second survey occurred well after that pulse had passed. A comparison of the time progression of the particle and larval trawl CPUE, therefore, suggests that the large pulse of LRS larvae in the reconstructed 2011 boundary condition was several days too early; had it been delayed, the number of particles representing LRS larvae in zone 1 would have increased between May 25 and June 22 (fig. 10). 

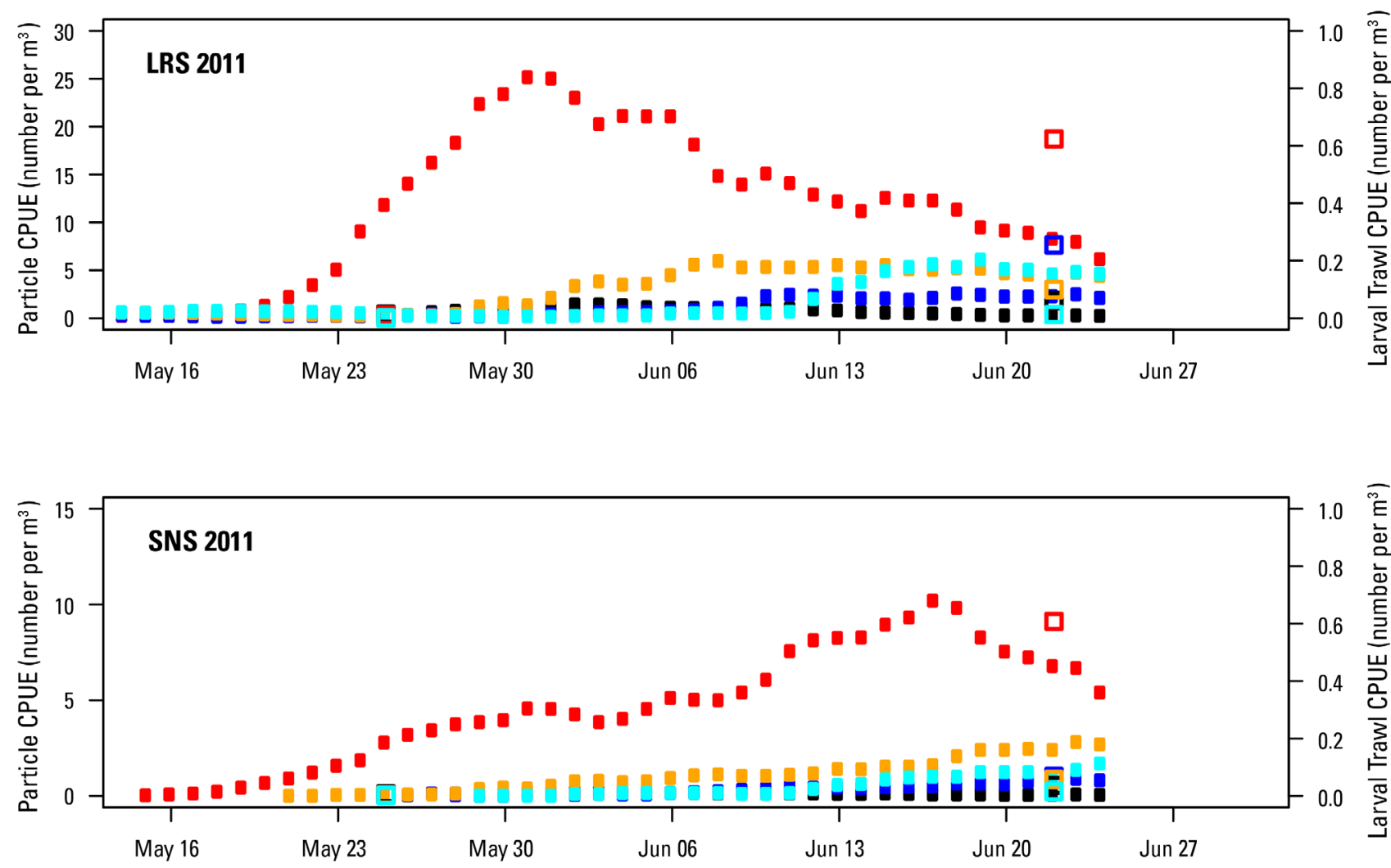

EXPLANATION

$$
\begin{array}{ll}
\text { - Particle counts, zone 0 } & \square \text { Larval counts, zone 0 } \\
\text { - Particle counts, zone 1 } & \square \text { Larval counts, zone 1 } \\
\text { - Particle counts, zone 2 } & \square \text { Larval counts, zone 2 } \\
\text { - Particle counts, zone 3 } & \square \text { Larval counts, zone 3 } \\
\text { - Particle counts, zone 4 } & \square \text { Larval counts, zone } 4
\end{array}
$$

Figure 10. Weekly catch per unit effort (CPUE) of particles representing Lost River sucker (LRS) larvae and shortnose sucker (SNS) larvae, and CPUE of larvae caught in nets during two larval trawl surveys in 2011, in each of five zones in Upper Klamath Lake, Oregon.

The larval trawl CPUE of both species was in general lower in 2012 than in 2011, particularly in zones 0 and 4 . The CPUE of both species caught in larval trawls decreased in zones 1-3 between the first (June 13) and second (June 27) surveys (fig. 11, table 3). The particle CPUE in each zone suggests that one reason for far fewer larvae being caught in the nets is that most of the larvae, especially the LRS larvae, passed through zones 1 and 3 before the first sampling survey took place. The particle CPUE representing LRS larvae decreased in each zone between the two surveys. The particle CPUE representing SNS larvae decreased in zone 1, but increased in zones 2 and 3 between the two surveys. A comparison of the time progression of the particle and larval trawl CPUE, therefore, suggests that the drift of SNS larvae in the Williamson River in 2012 was of shorter duration than indicated by the reconstructed 2012 boundary condition. 

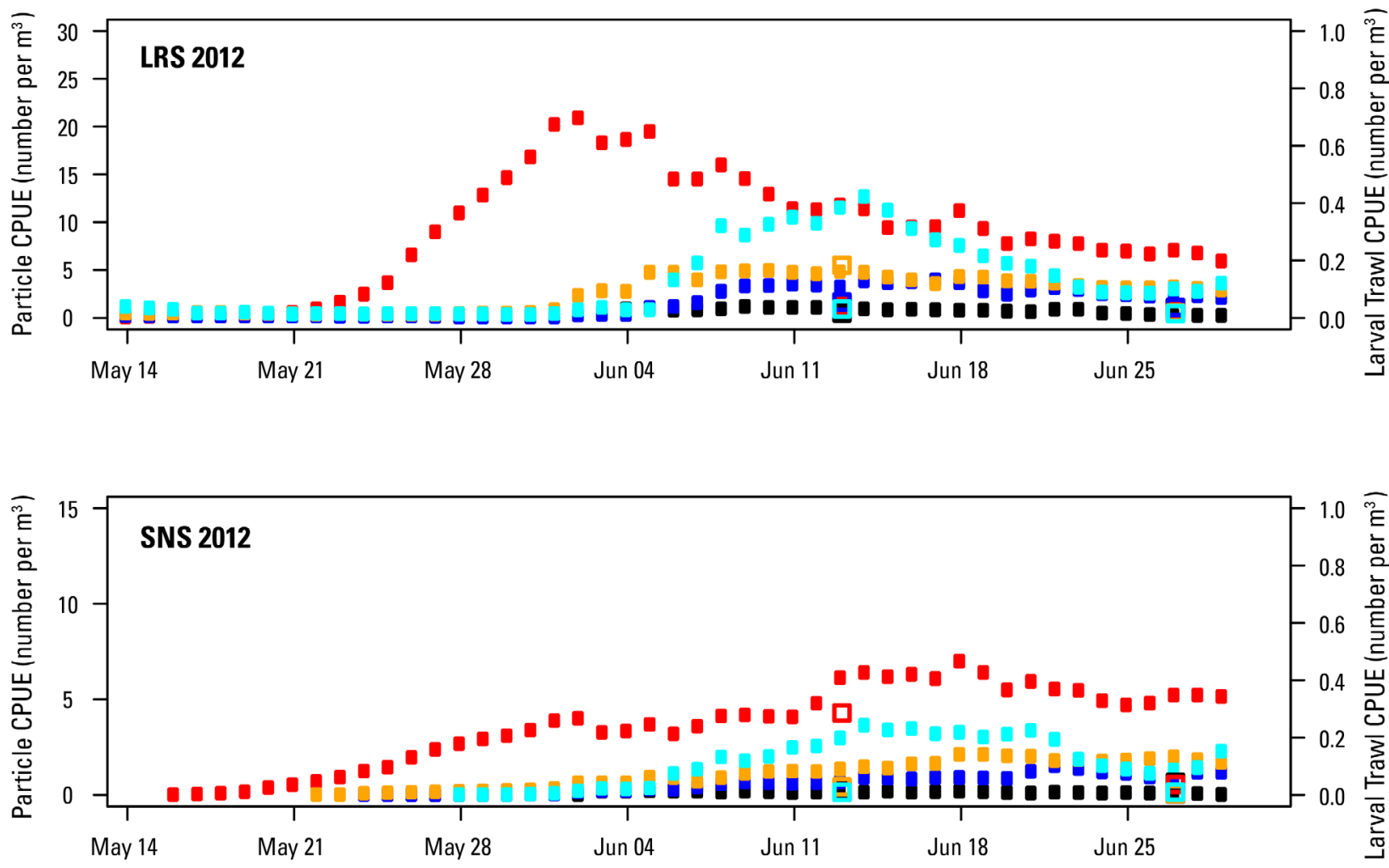

EXPLANATION

$\begin{array}{ll}\text { - Particle counts, zone 0 } & \square \text { Larval counts, zone } 0 \\ \text { - Particle counts, zone 1 } & \square \text { Larval counts, zone } 1 \\ \text { - Particle counts, zone 2 } & \square \text { Larval counts, zone 2 } \\ \text { - Particle counts, zone 3 } & \square \text { Larval counts, zone 3 } \\ \text { - Particle counts, zone 4 } & \square \text { Larval counts, zone 4 }\end{array}$

Figure 11. Weekly catch per unit effort (CPUE) of particles representing Lost River sucker (LRS) larvae and shortnose sucker (SNS) larvae, and CPUE of larvae caught in nets during two larval trawl surveys in 2012, in each of five zones in Upper Klamath Lake, Oregon. 
Table 3. Catch per unit effort (CPUE) of Lost River sucker and shortnose sucker larvae, as determined from 2011-2012 particle tracking simulations and larval trawls, Upper Klamath Lake, Oregon

\begin{tabular}{|c|c|c|c|c|c|c|c|c|c|c|}
\hline \multirow[t]{2}{*}{ Zone } & \multicolumn{5}{|c|}{ Simulated } & \multicolumn{5}{|c|}{ Observed } \\
\hline & $5 / 25 / 2011$ & Rank & $6 / 22 / 2011$ & Rank & Change & $5 / 25 / 2011$ & Rank & $6 / 22 / 2011$ & Rank & Change \\
\hline & \multicolumn{10}{|c|}{2011 Lost River sucker } \\
\hline 0 & 0.09 & 5 & 0.29 & 5 & + & 0.014 & 1 & 0.06 & 4 & + \\
\hline 1 & 11.81 & 1 & 8.30 & 1 & - & 0.011 & 2 & 0.62 & 1 & + \\
\hline 2 & 0.54 & 2 & 2.28 & 4 & + & NA & & 0.25 & 2 & NA \\
\hline 3 & 0.30 & 4 & 4.34 & 3 & + & 0.001 & 4 & 0.10 & 3 & + \\
\hline \multirow[t]{2}{*}{4} & 0.43 & 3 & 4.58 & 2 & + & 0.002 & 3 & 0.01 & 5 & + \\
\hline & \multicolumn{10}{|c|}{2011 shortnose sucker } \\
\hline 0 & 0.00 & 4.5 & 0.05 & 5 & + & 0.007 & 1 & 0.04 & 4 & + \\
\hline 1 & 2.78 & 1 & 6.79 & 1 & + & 0.002 & 3 & 0.61 & 1 & + \\
\hline 2 & 0.14 & 2 & 0.77 & 4 & + & NA & & 0.07 & 2 & NA \\
\hline 3 & 0.05 & 3 & 2.42 & 2 & + & 0.003 & 2 & 0.06 & 3 & + \\
\hline \multirow[t]{3}{*}{4} & 0.00 & 4.5 & 1.00 & 3 & + & 0.002 & 4 & 0.01 & 5 & + \\
\hline & $6 / 13 / 2012$ & rank & $6 / 27 / 2012$ & rank & Change & 6/13/2012 & rank & 6/27/2012 & rank & Change \\
\hline & \multicolumn{10}{|c|}{2012 Lost River sucker } \\
\hline 0 & 0.94 & 5 & 0.29 & 5 & - & 0.017 & 5 & 0.04 & 2 & + \\
\hline 1 & 11.79 & 1 & 7.05 & 1 & - & 0.047 & 3 & 0.03 & 3 & - \\
\hline 2 & 3.27 & 4 & 2.01 & 4 & - & 0.055 & 2 & 0.04 & 1 & - \\
\hline 3 & 4.80 & 3 & 3.24 & 2 & - & 0.183 & 1 & 0.02 & 4 & - \\
\hline \multirow[t]{2}{*}{4} & 11.54 & 2 & 2.99 & 3 & - & 0.031 & 4 & 0.02 & 5 & - \\
\hline & \multicolumn{10}{|c|}{2012 shortnose sucker } \\
\hline 0 & 0.14 & 5 & 0.08 & 5 & - & 0.017 & 3 & 0.04 & 1 & + \\
\hline 1 & 6.12 & 1 & 5.20 & 1 & - & 0.286 & 1 & 0.04 & 2 & - \\
\hline 2 & 0.68 & 4 & 0.92 & 4 & + & 0.009 & 5 & 0.00 & 5 & - \\
\hline 3 & 1.33 & 3 & 1.97 & 2 & + & 0.028 & 2 & 0.00 & 4 & - \\
\hline 4 & 2.98 & 2 & 1.31 & 3 & - & 0.009 & 4 & 0.01 & 3 & + \\
\hline
\end{tabular}


Particles representing LRS larvae spawned at shoreline springs were simulated to enter the model domain starting in April and through most of May in both 2011 and 2012; the difference between the two years was that the pulse of springs larvae was delayed by 5 days in 2012 relative to 2011 (fig. 7). Those particles were distributed through zones 1-4, and their length (as determined from particle age and the length-at-age regression) increased steadily through time until the last week in May (zones 1 and 2) or the first week in June (zones 3 and 4), when the larger pulse of particles representing LRS larvae from spawning grounds in upstream tributaries entered the system. At those respective times, the length distribution of particles shifted downward to represent the influx of "younger" particles (figs. 12, 13). During the remaining weeks of the simulation, the length distribution of particles increased steadily in most zones as the majority of the particles representing LRS larvae already were in the model domain and were growing with time. The median length of the particles in each zone increased between the two larval trawl sampling dates in 2011 (May 25 and June 22) and in 2012 (June 13 and June 27). The median length of larvae caught in the larval trawls also increased in each zone between the two sampling dates, with the exception of zone 0 in 2012 (table 4), indicating that those larvae already in the system were aging and that there was not a large influx of younger larvae into the system between the two sampling dates. Therefore, the progression of length of Lost River sucker larvae through time was broadly consistent between the simulations and the net catches, with the caveat that the temporal resolution of the net catches was limited in comparison to the simulations. 


\section{1}
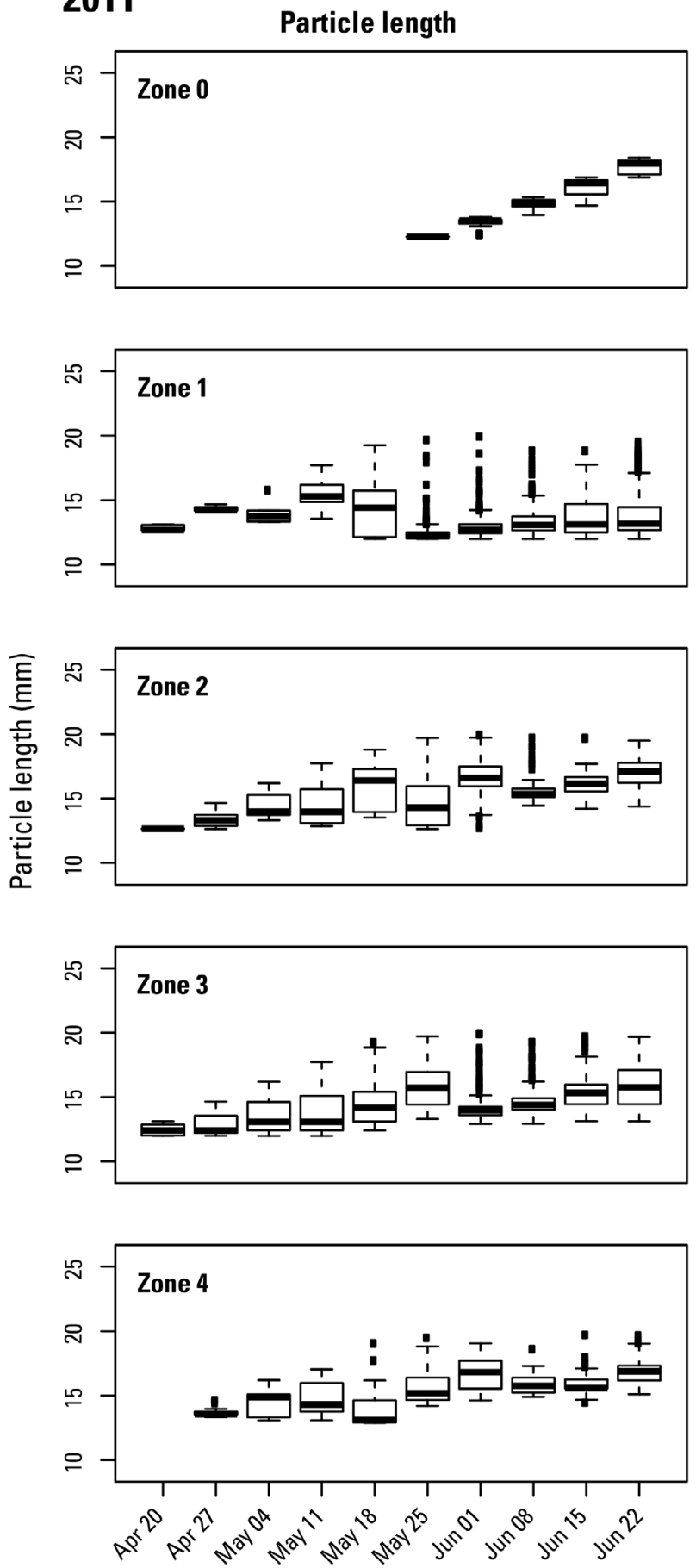
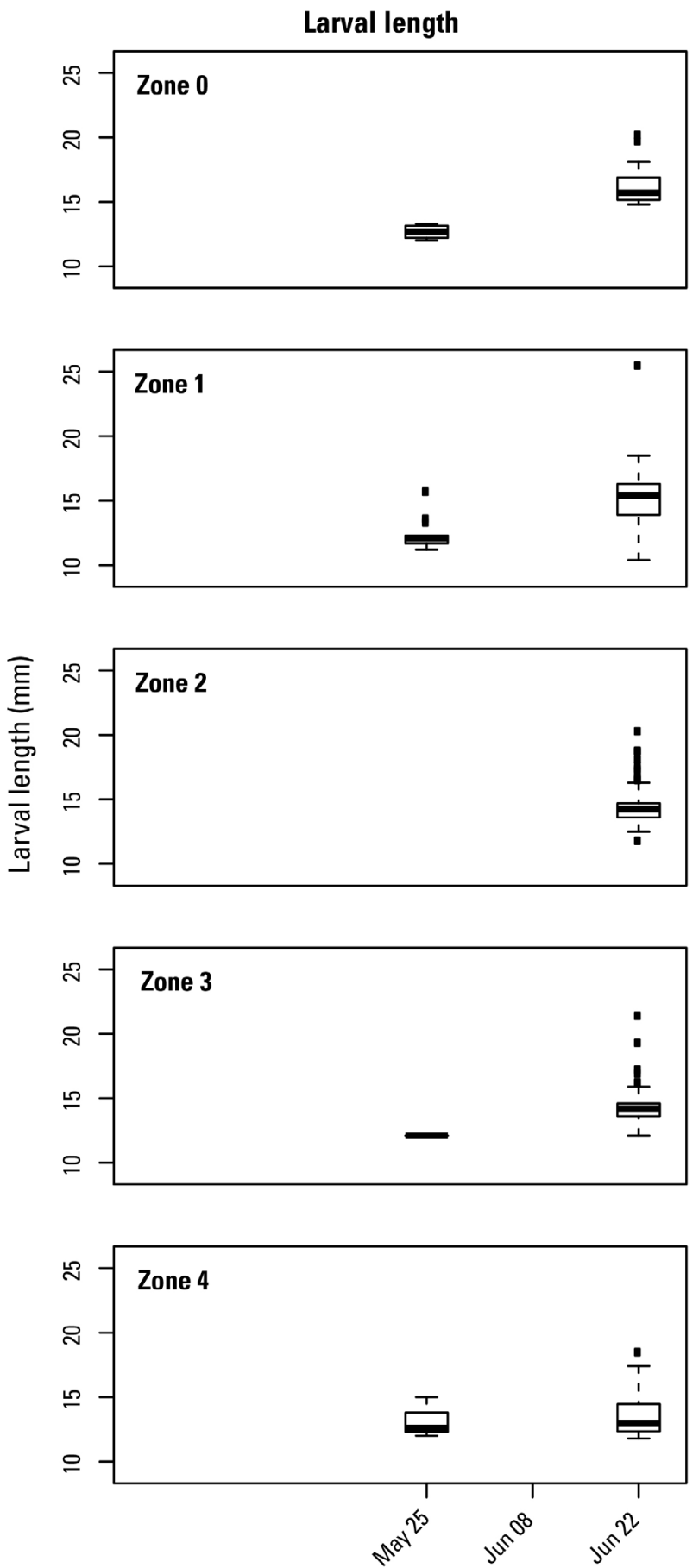

Figure 12. Weekly length distributions of Lost River sucker larvae in 2011, as determined from particle-tracking simulations and from larval trawls, Upper Klamath Lake, Oregon. Whiskers on boxes are 1.5 times the interquartile range. 
2012
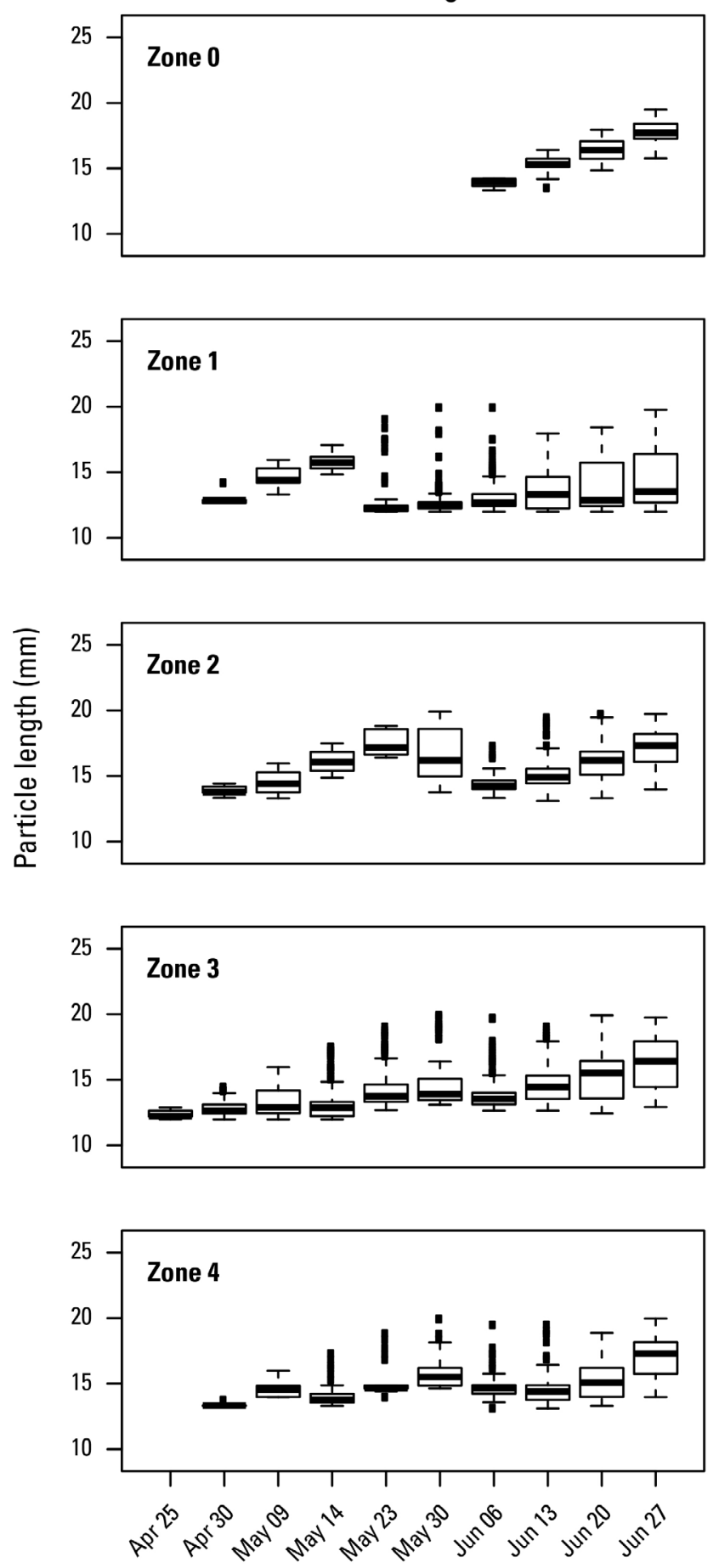

Larval length
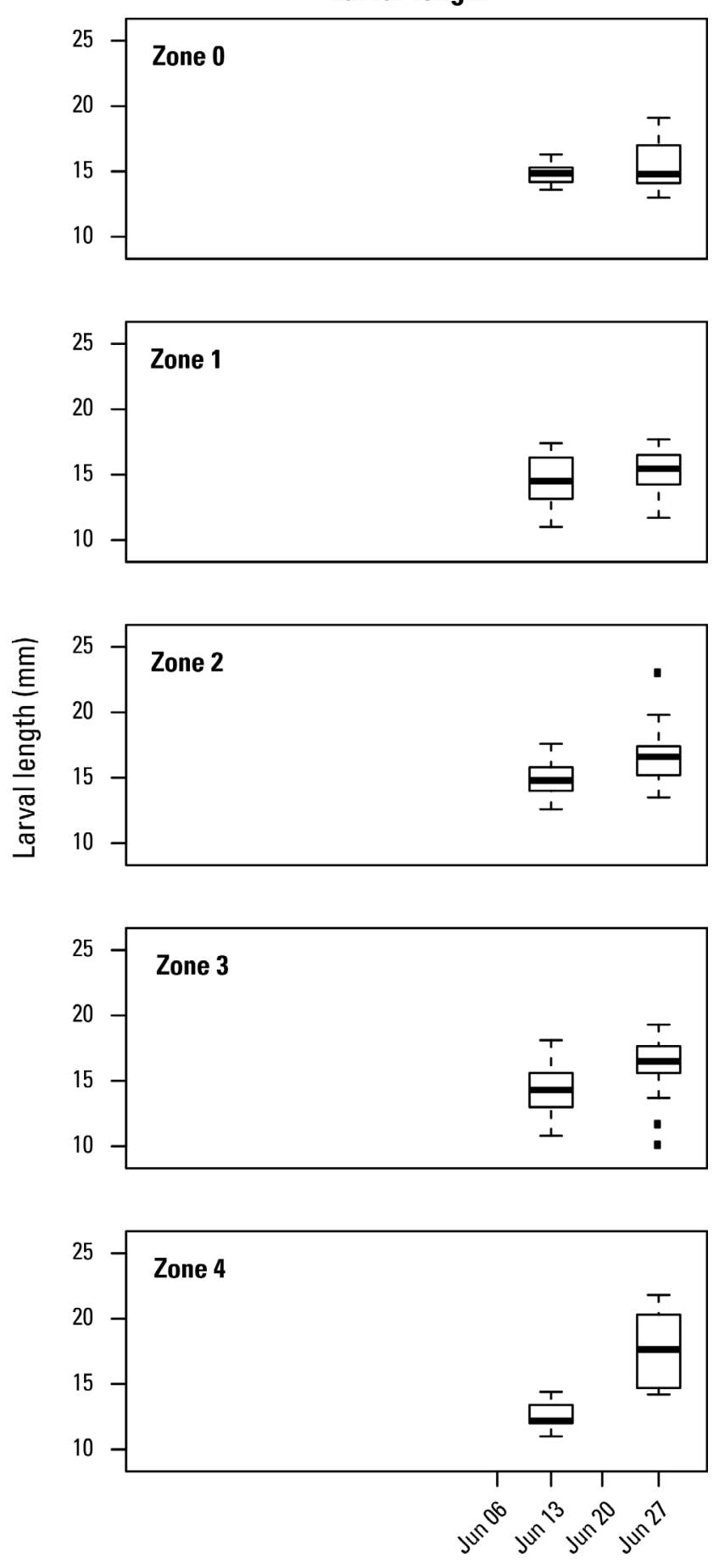

Figure 13. Weekly length distributions of Lost River sucker larvae in 2012, as determined from particle-tracking simulations and from larval trawls, Upper Klamath Lake, Oregon. Whiskers on boxes are 1.5 times the interquartile range. 
Table 4. Median length of Lost River and shortnose sucker larvae (in millimeters), as determined from particle-tracking simulations and from larval trawls, Upper Klamath Lake, Oregon, 2011-12.

\begin{tabular}{|c|c|c|c|c|c|c|c|c|c|c|}
\hline \multirow[t]{2}{*}{ Zone } & \multicolumn{5}{|c|}{ Simulated } & \multicolumn{5}{|c|}{ Observed } \\
\hline & $5 / 25 / 2011$ & Rank & $6 / 22 / 2011$ & Rank & Change & $5 / 25 / 2011$ & Rank & $6 / 22 / 2011$ & Rank & Change \\
\hline & \multicolumn{10}{|c|}{2011 Lost River sucker } \\
\hline 0 & 12.3 & 2 & 17.9 & 5 & 5.7 & 12.7 & 4 & 15.7 & 5 & 3.0 \\
\hline 1 & 12.2 & 1 & 13.2 & 1 & 1.0 & 12.1 & 1.5 & 15.4 & 4 & 3.3 \\
\hline 2 & 14.3 & 3 & 17.1 & 4 & 2.8 & -- & & 14.3 & 3 & -- \\
\hline 3 & 15.7 & 5 & 15.8 & 2 & 0.0 & 12.1 & 1.5 & 14.2 & 2 & 2.1 \\
\hline \multirow[t]{2}{*}{4} & 15.2 & 4 & 16.9 & 3 & 1.7 & 12.6 & 3 & 13.0 & 1 & 0.4 \\
\hline & \multicolumn{10}{|c|}{2011 shortnose sucker } \\
\hline 0 & -- & & 17.4 & 5 & -- & 12.8 & 2 & 15.8 & 5 & 3.1 \\
\hline 1 & 12.4 & 1 & 13.1 & 1 & 0.7 & 12.3 & 1 & 13.5 & 4 & 1.3 \\
\hline 2 & 13.1 & 2 & 16.2 & 3 & 3.1 & -- & & 13.4 & 3 & -- \\
\hline 3 & 13.6 & 3 & 14.4 & 2 & 0.9 & 13.0 & 3 & 13.3 & 2 & 0.3 \\
\hline 4 & -- & & 16.6 & 4 & -- & 14.3 & 4 & 12.7 & 1 & -1.7 \\
\hline
\end{tabular}

\begin{tabular}{|c|c|c|c|c|c|c|c|c|c|c|}
\hline & $6 / 13 / 2012$ & Rank & $6 / 27 / 2012$ & Rank & Change & $6 / 13 / 2012$ & Rank & $6 / 27 / 2012$ & Rank & Change \\
\hline & \multicolumn{10}{|c|}{2012 Lost River sucker } \\
\hline 0 & 15.3 & 5 & 17.7 & 5 & 2.4 & 14.9 & 5 & 14.8 & 1 & -0.1 \\
\hline 1 & 13.3 & 1 & 13.5 & 1 & 0.2 & 14.5 & 3 & 15.5 & 2 & 0.9 \\
\hline 2 & 14.9 & 4 & 17.3 & 4 & 2.4 & 14.8 & 4 & 16.6 & 4 & 1.8 \\
\hline 3 & 14.5 & 3 & 16.4 & 2 & 2.0 & 14.3 & 2 & 16.5 & 3 & 2.2 \\
\hline 4 & 14.4 & 2 & 17.3 & 3 & 2.9 & 12.2 & 1 & 17.7 & 5 & 5.5 \\
\hline & \multicolumn{10}{|c|}{2012 shortnose sucker } \\
\hline 0 & 15.2 & 5 & 18.2 & 5 & 3.0 & 13.7 & 5 & 14.1 & 3 & 0.5 \\
\hline 1 & 12.2 & 1 & 13.1 & 1 & 0.9 & 13.0 & 2 & 12.6 & 1 & -0.4 \\
\hline 2 & 15.1 & 4 & 15.5 & 3 & 0.4 & 12.9 & 1 & 13.4 & 2 & 0.5 \\
\hline 3 & 13.8 & 2 & 14.6 & 2 & 0.8 & 13.1 & 3 & 14.4 & 4 & 1.3 \\
\hline 4 & 14.0 & 3 & 15.5 & 4 & 1.5 & 13.4 & 4 & 19.2 & 5 & 5.8 \\
\hline
\end{tabular}


Particles representing SNS larvae were inserted into the model domain starting in the third week in May in both 2011 and 2012, and were not dispersed through all the zones until early June (figs. 14, 15). Because the insertion of particles representing shortnose sucker larvae into the model domain at the Williamson River generally occurred more evenly and over a longer period of time than the insertion of particles representing LRS larvae, the progression of increasing length through time was more systematic for particles representing SNS larvae than for particles representing LRS larvae, particularly in zones 1 and 3 in 2011 (fig. 14). In 2012, the June 14 peak in particles representing SNS larvae entering the model domain is evident in the length distribution in zone 1, and a week later in zone 3 (fig. 15). The median length of the particles in zones 1,2 and 3 increased between the two larval trawl sampling dates in 2011 (May 25 and June 22), and increased in all zones between the sampling dates in 2012 (June 13 and June 27). The median length of larvae caught in the trawls also increased between the two sampling dates in each zone where data were available, with the exception of zone 1 in 2012 (table 4), indicating that, for the most part, the second sampling collected largely larvae that had been in the lake since the first sampling and were aging, rather than a large influx of younger larvae into the lake between the two sampling dates. The exception of zone 1 in 2012 could indicate that there was a late pulse of SNS larvae entering the lake that was not included in the reconstruction of the 2012 boundary condition. Overall, the progression of length of shortnose larvae through time was broadly consistent between the simulations and the net catches, with the caveat that the temporal resolution of the net catches was limited in comparison to the simulations.
For both species, the progression of length of tracked particles through zones increased with the distance away from the source of the larvae in the Williamson River Delta, such that zone 1 always had the shortest median length, and zone 3 usually had the second-shortest median length (table 4), with the exception of the earliest sampling date in 2011 when the particles in the model domain primarily were those representing LRS larvae from the eastern shoreline springs. The progression of length through zones 1 and 3 is a result of the predominant transport pathways from the river delta along the eastern shoreline to the south. Zones 2 and 4 generally had either the third- or fourth-ranked median lengths, reflecting greater distance from the source in the Williamson River Delta along predominant transport pathways, and the fact that these zones contain more of a mix of particles of different ages than the other zones. The longest median length generally was for particles in zone 5, reflecting the long and varied pathways that most particles that reach Agency Lake take through the Williamson River Delta and Upper Klamath Lake. The median lengths of fish from the larval trawls do not, in general, support as straightforward an interpretation as the tracked particles. The shortest fish were found in each zone, depending on species and sampling date, and zone 1 fish were ranked from 1 to 4 in median length, depending on species and sampling date. The progression of increasing length from zone 1 to zone 3 that is strongly supported by the transport pathways of the particles is not always seen in the net catches: in three of the eight species-date combinations, the median length stayed the same or decreased between zone 1 and zone 3 (table 4). Therefore, the progression of length of larvae (both species) through zones was not consistent between the simulations and the net catches. 
2011
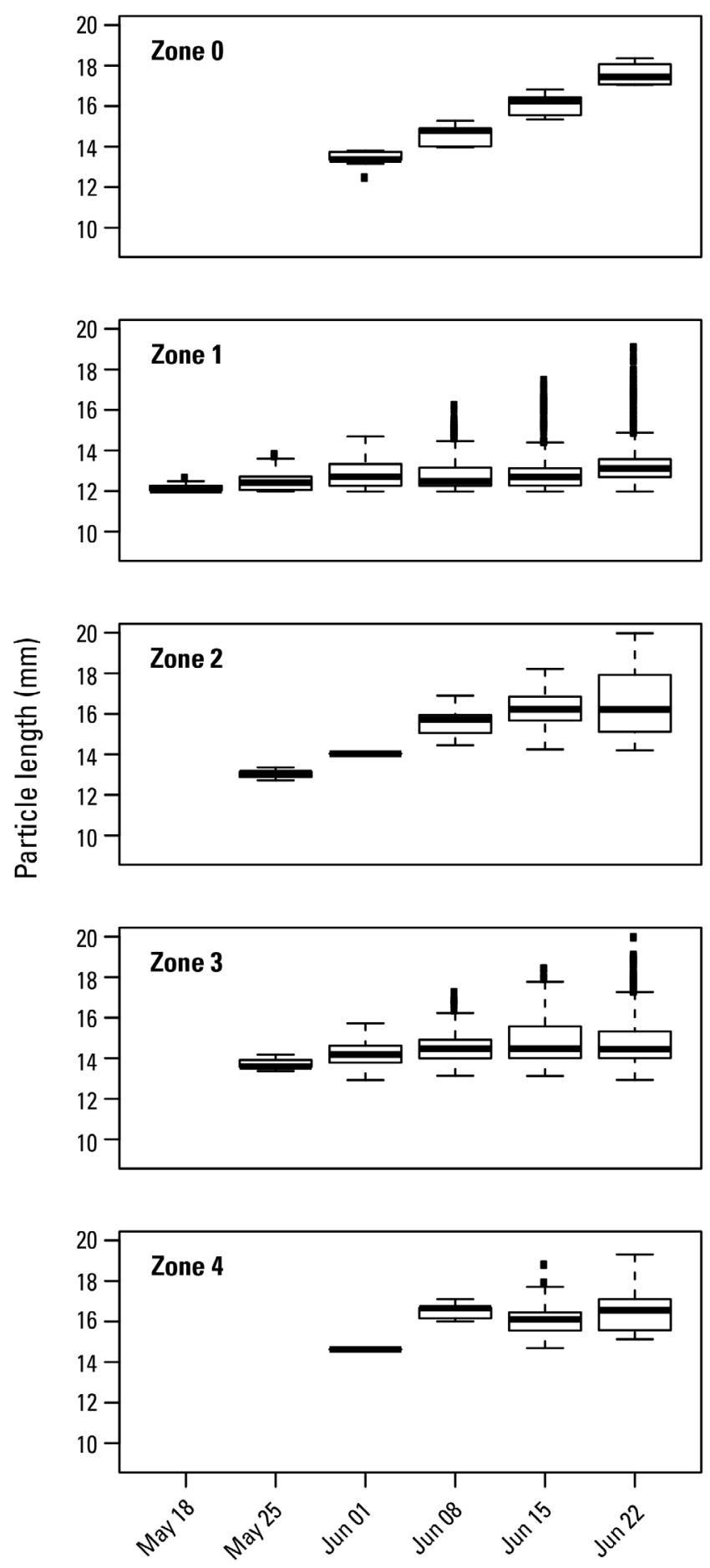

\section{Larval length}
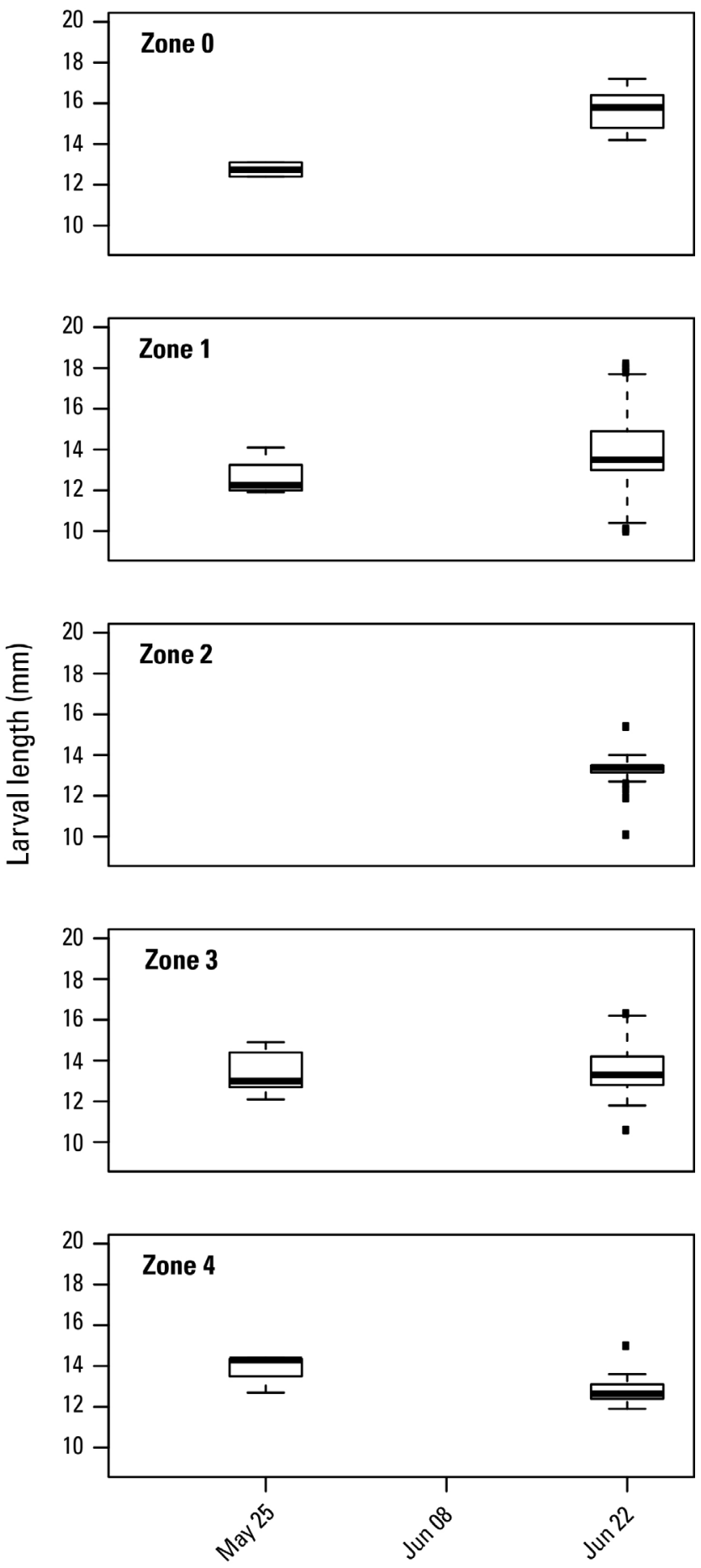

Figure 14. Weekly length distributions of shortnose sucker larvae in 2011, as determined from particle-tracking simulations and from larval trawls, Upper Klamath Lake, Oregon. Whiskers on boxes are 1.5 times the interquartile range. 


\section{2}
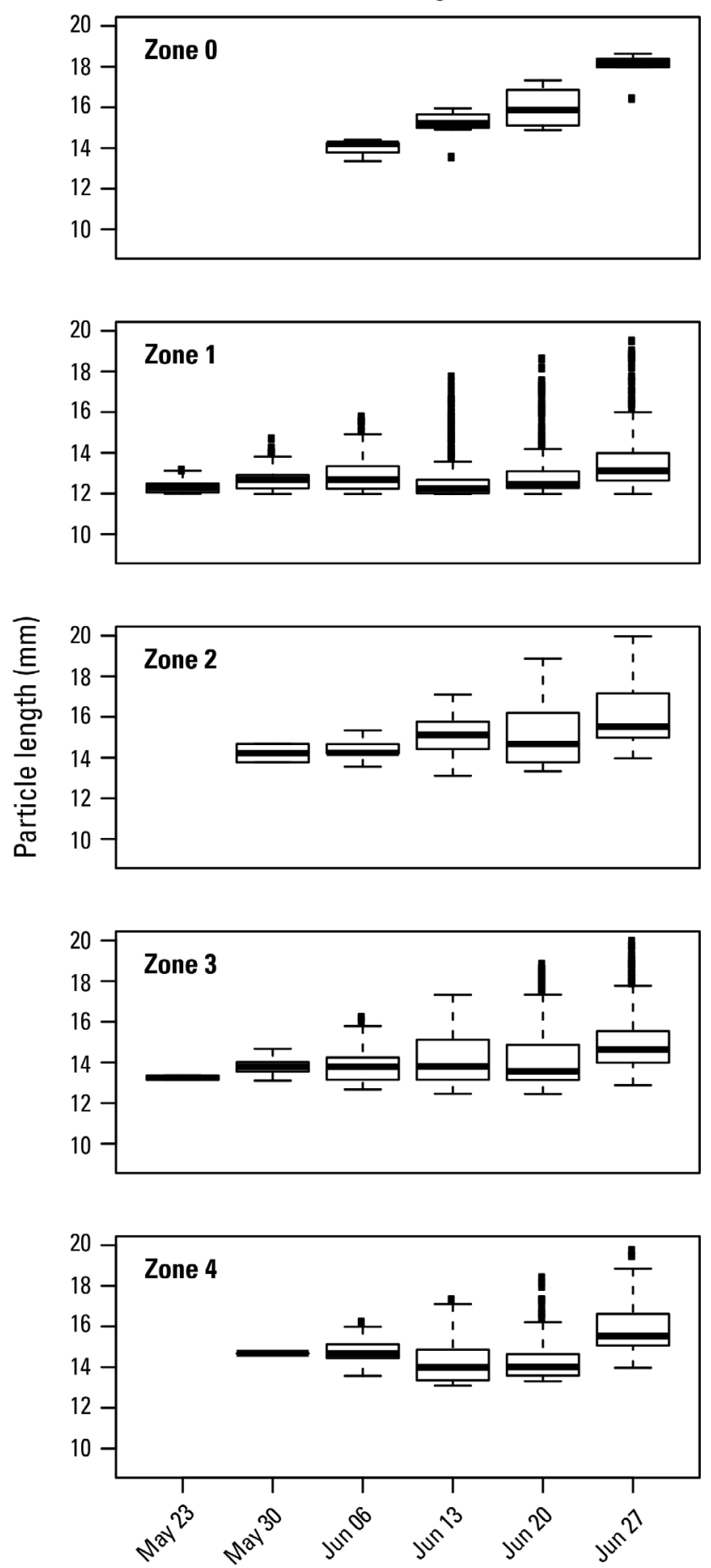

Larval length
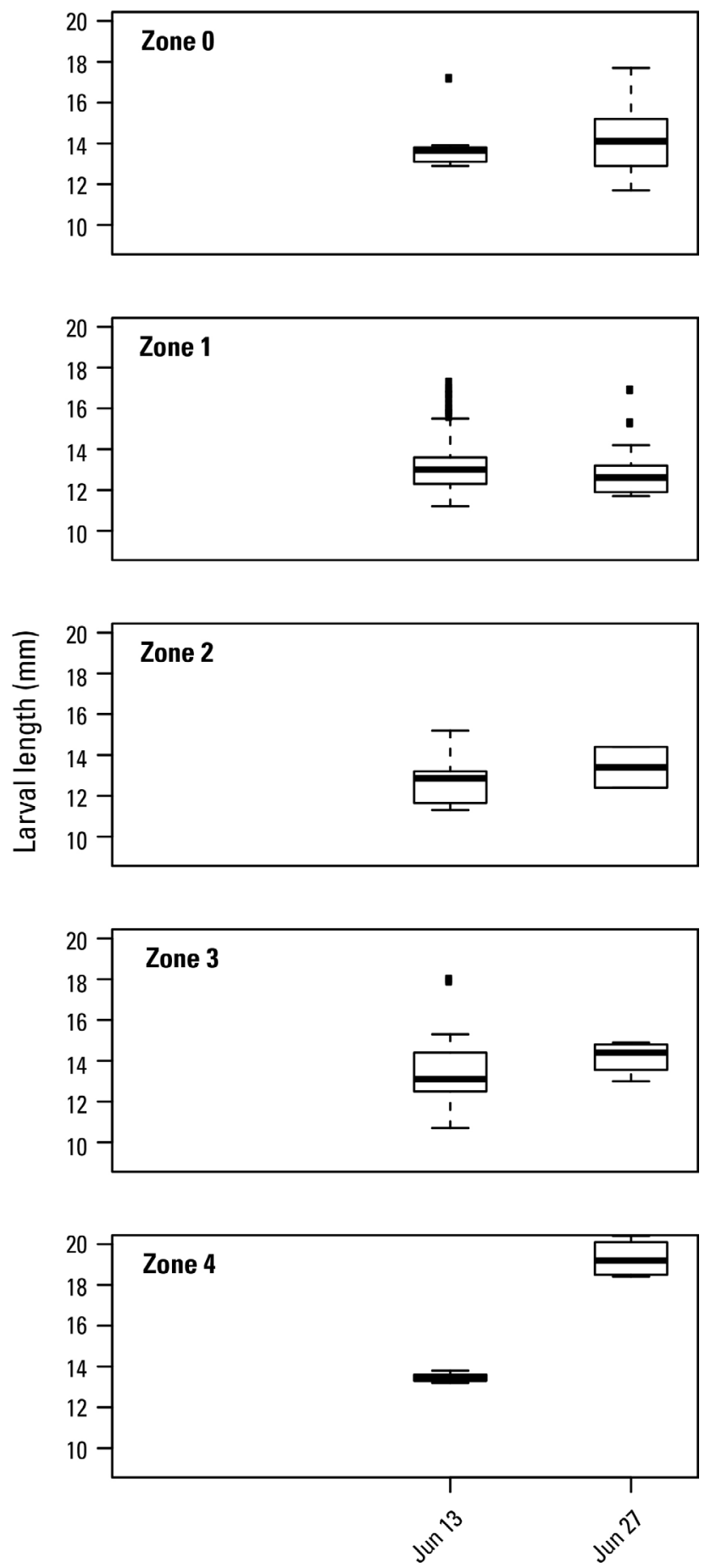

Figure 15. Weekly length distributions of shortnose sucker larvae in 2012, as determined from particle-tracking simulations and from larval trawls, Upper Klamath Lake, Oregon. Whiskers on boxes are 1.5 times the interquartile range. 
The combined temporal and spatial comparison of the length of tracked particles and the length of larval trawl catches were assessed quantitatively with a correlation analysis (table 5). The correlation between simulated fish lengths as determined by particle tracking with lengths of fish caught in larval trawls was significant $(p<0.05)$ for both species in 2011 (Spearman $\rho 0.33$ for LRS and 0.60 for SNS; table 5), and significant for LRS only in 2012 (Spearman $\rho$ 0.37; table 5). When data from both years were combined, the correlation was significant for both species (Spearman $\rho 0.34$ for LRS and 0.44 for SNS). There was a consistent positive bias in lengths, such that the lengths determined from particle tracking were longer than the lengths of fish

Table 5. Spearman correlation coefficients relating the simulated length of Lost River sucker (LRS) and shortnose sucker (SNS) larvae, as determined from particle tracking simulations to the length of Lost River and shortnose sucker larvae caught in larval trawls, Upper Klamath Lake, Oregon.

\begin{tabular}{lcccc}
\hline Species & $\begin{array}{c}\text { Spearman } \\
\mathbf{\rho}\end{array}$ & $\mathbf{p}$ & $\mathbf{N}$ & $\begin{array}{c}\text { Bias } \\
(\mathbf{m m})\end{array}$ \\
\hline SNS & \multicolumn{3}{c}{$\mathbf{2 0 1 1}$} \\
LRS & $\mathbf{0 . 6 0}$ & 0.0018 & 24 & 1.1 \\
All fish & $\mathbf{0 . 3 3}$ & 0.0399 & 38 & 1.1 \\
\hline \multicolumn{7}{c}{$\mathbf{0 . 3 4}$} & 0.0069 & 62 & 1.9 \\
\hline SNS & 0.12 & 0.6356 & 17 & 0.3 \\
LRS & $\mathbf{0 . 3 7}$ & 0.0023 & 66 & 0.2 \\
All fish & $\mathbf{0 . 4 3}$ & 0.0001 & 80 & 0.3 \\
\hline \multicolumn{5}{c}{$\mathbf{2 0 1 1}-2012$} \\
SNS & $\mathbf{0 . 4 4}$ & 0.0040 & 41 & 0.7 \\
LRS & $\mathbf{0 . 3 4}$ & 0.0004 & 104 & 0.6 \\
All fish & $\mathbf{0 . 4 4}$ & 0.0000 & 145 & 0.6 \\
\hline
\end{tabular}

caught in the larval trawls. The bias was larger (1.1 $\mathrm{mm}$ for both species) in 2011 than in 2012, and amounted to about 5 days of growth based on the length-at-age regression. Therefore, a lag of about 5 days in the reconstructed boundary condition largely would eliminate this bias. The comparison of particle and larval trawl CPUE discussed above indicated that the reconstructed 2011 boundary condition might have been too early by several days, so this bias is also consistent with the previous comparison. The bias in 2012 was $0.3 \mathrm{~mm}$ for SNS larvae and $0.2 \mathrm{~mm}$ for LRS larvae, amounting to less than a day of growth for each species, and indicating that the timing of the reconstructed boundary condition in 2012 was more accurate. 


\section{Sensitivity of Particle Retention to Wind, River Discharge, and Lake Elevation}

\section{Particle Retention-Spawning at Springs}

The results of the particle-retention experiments were summarized with a cumulative count of the fraction of particles that exited the model domain as a function of time since the particles were inserted. An estimate of the precision of this cumulative count of particles for particles inserted at shoreline springs was obtained by running three model simulations using the same set of conditions - particle group, lake elevation (ELEV), and Williamson River discharge (DISCH) - that were denoted as "replicate" simulations. This was done for three sets of conditions, and the standard deviation of the replicates was calculated at 10 and 15 days after insertion of particles. Standard deviations of $0.004,0.016$, and 0.024 were obtained at 10 days, and standard deviations of $0.028,0.008$, and 0.009 were obtained at 15 days. Using this method, therefore, a reasonably conservative estimate of the precision of the cumulative fractions is 0.025 , or 2.5 percent.

Particles that were inserted into the model domain at the eastern shoreline springs began to exit at the southern end of the lake between about 5 and 10 days after the group was insert- ed, when ELEV was 4,142.5 ft and DISCH was $75 \mathrm{~m}^{3} / \mathrm{s}$, depending on the group (fig. 16). Group $\mathrm{S} 1$, characterized by primarily westerly winds and the most representative of average April conditions, started to exit the domain later than groups S2 and S3, both of which were characterized by winds primarily from the northwest. By 18 days after entry (when ELEV was $4,142.5 \mathrm{ft}$ and DISCH was $75 \mathrm{~m}^{3} / \mathrm{s}$ ), $57 \%$ (group S1), $88 \%$ (group S2), and 100\% (group S3) of the particles had left the domain through the outlet of the lake, and the exit of particles leveled off after that point. The wind scenario, therefore, was a strongly determining factor in how quickly, and ultimately how many, particles left the domain. Williamson River discharge also was a determining factor, such that higher discharge resultresulted in particles starting to exit the domain sooner and, ultimately, in more particles leaving. By 20 days after entry (when ELEV was 4,142.5 ft), $18 \%$ (DISCH $20 \mathrm{~m}^{3} / \mathrm{s}$ ), 38\% (DISCH 50 $\mathrm{m}^{3} / \mathrm{s}$ ), 59\% (DISCH $75 \mathrm{~m}^{3} / \mathrm{s}$ ), and $84 \%$ (DISCH $100 \mathrm{~m}^{3} / \mathrm{s}$ ) of the particles in group S1 had exited the domain (fig. 17). By comparison, lake elevation was not a strongly determining factor. By 20 days after entry (when DISCH was $75 \mathrm{~m}^{3} / \mathrm{s}$ ), $56 \%$ (ELEV 4,140.5 ft), 60\% (ELEV 4,141.5 ft), $59 \%$ (ELEV 4,142.5 ft), and 67\% (ELEV 4,143.3 $\mathrm{ft}$ ) of the particles in group S2 had exited the domain (fig. 18).

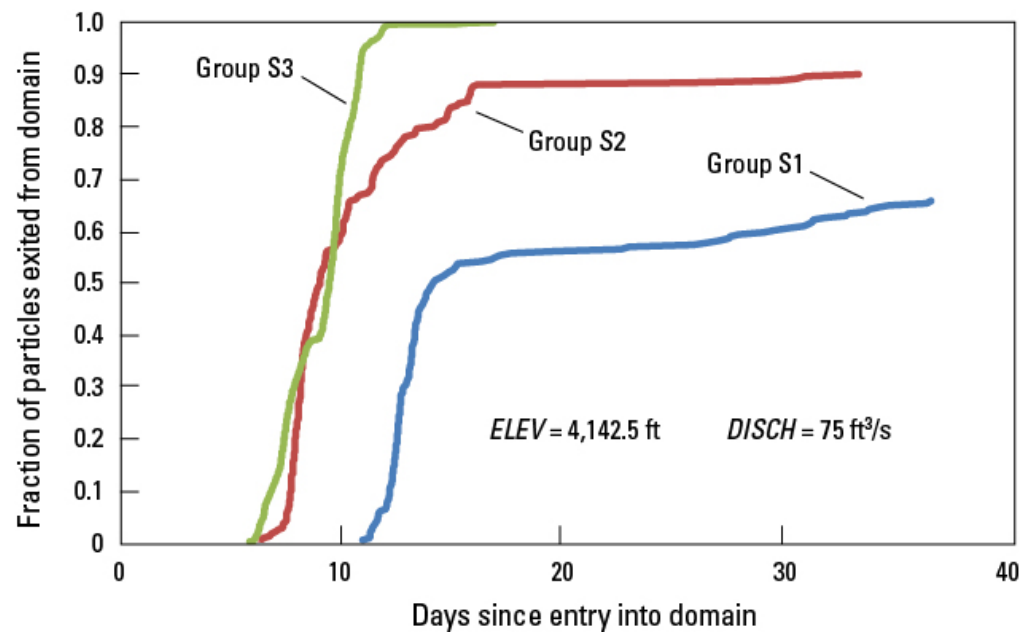

Figure 16. Fraction of particles that exited the model domain as a function of time since the particle group was inserted into the simulation, for particle groups inserted at eastern shoreline springs, Upper Klamath Lake, Oregon. In each case, the lake elevation (ELEV) was 4,142.5 feet and the Williamson River discharge $(D / S C H)$ was 75 cubic meters per second. 


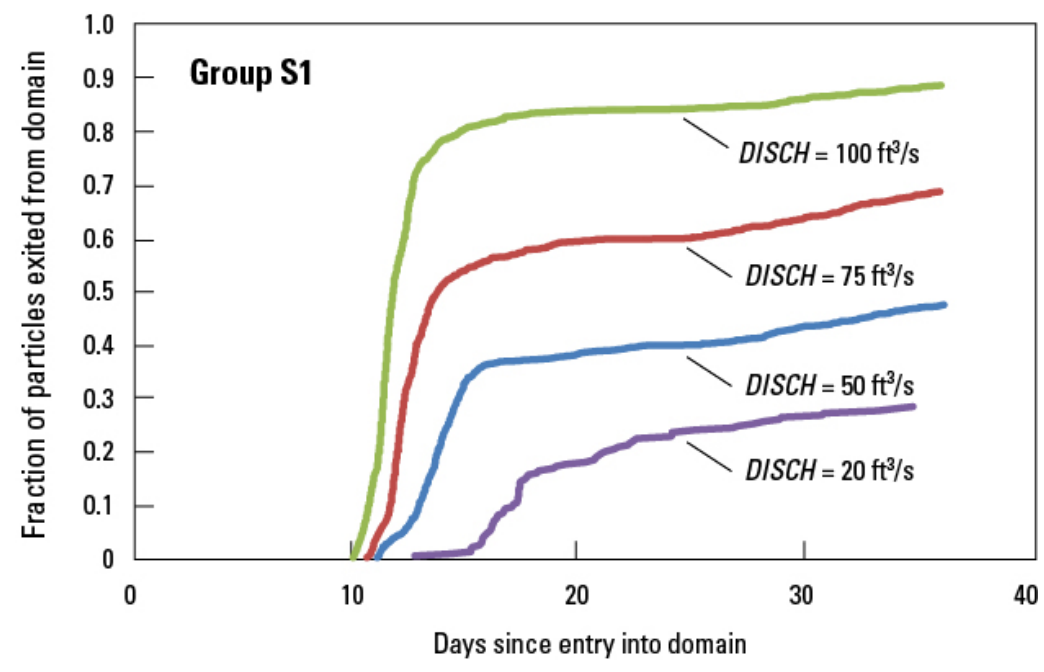

Figure 17. Fraction of particles that exited the model domain as a function of time since the particle group was inserted into the simulation, for particle group S1, inserted at eastern shoreline springs, Upper Klamath Lake, Oregon. In each case, the lake elevation was 4,142.5 feet. The comparison is across four Williamson River discharges (DISCH) from 20 to 100 cubic meters per second.

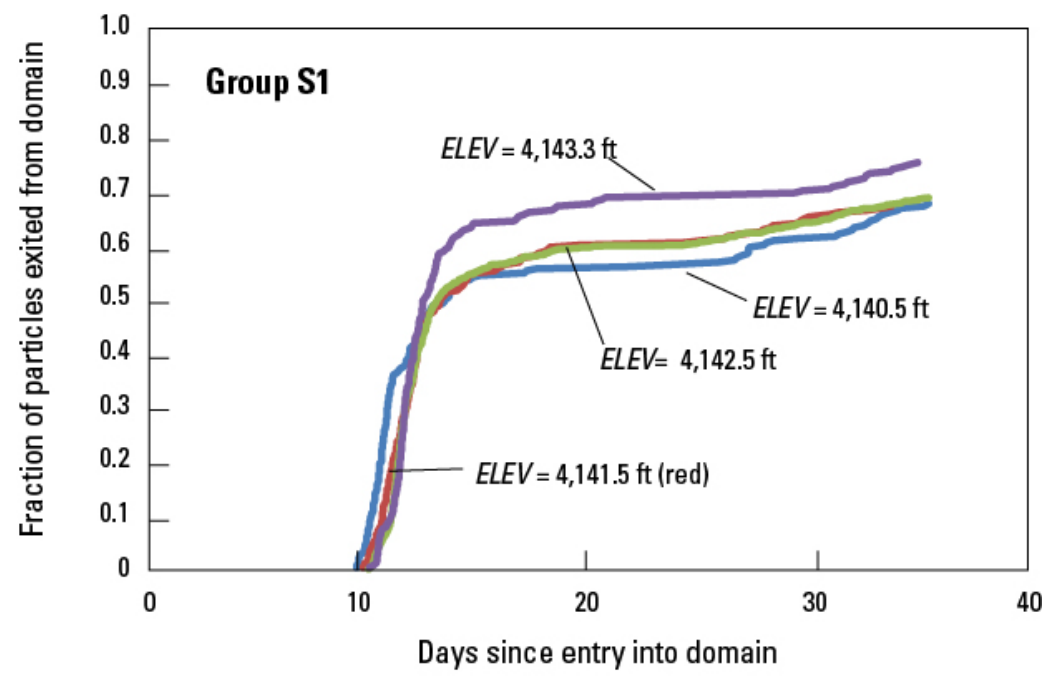

Figure 18. Fraction of particles that exited the model domain as a function of time since the particle group was inserted into the simulation, for particle group S1, inserted at eastern shoreline springs, Upper Klamath Lake, Oregon. In each case, the Williamson River discharge was 75 cubic meters per second. The comparison is across four lake elevations (ELEV) from 4,140.5 to 4,143.3 feet.
Particles released together as a group tended to travel as a "cloud" southeast from the location of the springs along the shoreline with the prevailing wind-driven circulation. The cloud of particles did not have time to disperse significantly because of the short distance between the shoreline springs and the southern end of Upper Klamath Lake. When the cloud reached the southern end of the lake, particles exited the domain rapidly for a few days, and then the rate of exit slowed, after which few particles exited. The effect of increasing lake elevation for a given combination of river discharge and wind scenario generally was to delay the start of the rapid exit of particles. For group S2 and $\mathrm{S} 3$ particles, that phase started about 5-7 days from the time of insertion; as a result, the cumulative fraction of particles in group S1 that exited the domain by 10 days since entry and the fraction of particles in groups S2 and S3 that exited by 6 days since entry decreased with increasing elevation at all values of river discharge (table 6). Beyond the initial rapid exit phase that lasted only $1-2$ days, however, the effect of lake elevation was small and unpredictable, as particle pathways became complicated functions of lake elevation, discharge, and wind-driven circulation patterns. This is demonstrated by the relation between lake elevation and the cumulative fraction of group S1 particles that exited by 15 days since entry, and between lake elevation and group S2 particles that exited by 10 days since entry (table 6). At higher values of river discharge (75 and $100 \mathrm{~m}^{3} / \mathrm{s}$ ), nearly all group S3 particles had exited by 10 days, regardless of the value of lake elevation. 
Table 6. Fraction of particles that has exited the model domain by 6,10 , and 15 days since the particle group was inserted into the model simulation (blue bars), as a function of Upper Klamath Lake elevation and Williamson River discharge, for particle groups inserted at eastern shoreline springs, Upper Klamath Lake, Oregon.

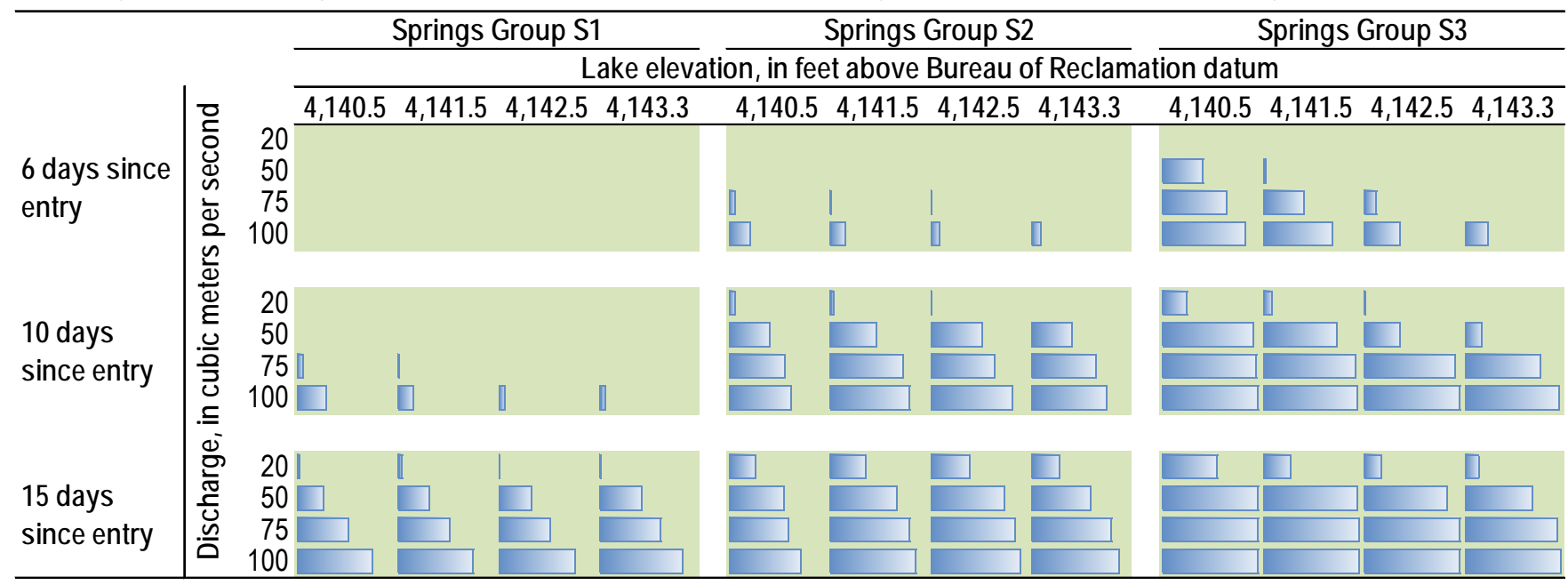

\section{Particle Retention-Spawning in Williamson River}

An estimate of the precision of the cumulative count of particles for particles inserted in the river was obtained by running three model simulations using the same set of conditions-particle group, ELEV, and DISCH - that were denoted as "replicate" simulations. The standard deviations of the replicates at 15 and 25 days after insertion of particles were 0.036 and 0.038 , respectively. Using this method, therefore, a reasonable estimate of the precision of the cumulative fractions is 0.037 , or 3.7 percent.

Particles that were inserted into the model domain at the Williamson River boundary, representing drift from spawning grounds upstream of the Modoc Point Road bridge, began to exit at the southern end of the lake between approximately 10 and 15 days after the group was inserted, when ELEV was 4,142.5 ft and DISCH was $50 \mathrm{~m} 3 / \mathrm{s}$, depending on the group (fig. 19). Groups R1 and R2, which were characterized primarily by moderate-to-strong westerly winds, started to exit the domain later than group R2, which was characterized by moderate winds primarily from the northwest. Particles from group R1, the only group that experienced a period of strong counter-prevailing winds, left the domain at an overall slower rate than particles from group R2 or R3. By 25 days after entry (when $E L E V$ was $4,142.5 \mathrm{ft}$ and DISCH was 50 $\mathrm{m}^{3} / \mathrm{s}$ ), $25 \%$ (group R1), 68\% (group R2), and $66 \%$ (group R3) of the particles had left the domain, and the exit rate of particles slowed after that point. The wind scenario, therefore, was a strongly determining factor in how quickly, and ultimately how many, particles left the domain. Williamson River discharge also was a strong determining factor, such that stronger discharge resulted in particles starting to exit the domain sooner and exiting at a more rapid rate (fig. 20). By 25 days after entry (when ELEV was 4,142.5 ft), $0 \%$ (DISCH $20 \mathrm{~m} 3 / \mathrm{s}$ ), 25\% (DISCH 50 $\mathrm{m} 3 / \mathrm{s}$ ), $50 \%$ (DISCH $75 \mathrm{m3} / \mathrm{s}$ ), and 63\% (DISCH $100 \mathrm{~m} 3 / \mathrm{s}$ ) of the particles in group R1 had exited the domain. By comparison, lake elevation was a smaller determining factor, such that the start of the exit of particles was delayed as lake elevation increased (fig. 21). By 25 days after entry (when DISCH was $50 \mathrm{~m} 3 / \mathrm{s}$ ), 36\% (ELEV 4,140.5 ft), 34\% (ELEV 4141.5 ft), 25\% (ELEV $4142.5 \mathrm{ft}$ ), and $14 \%$ (ELEV 4,143.3 ft) of the particles in group R1 had left the domain. 

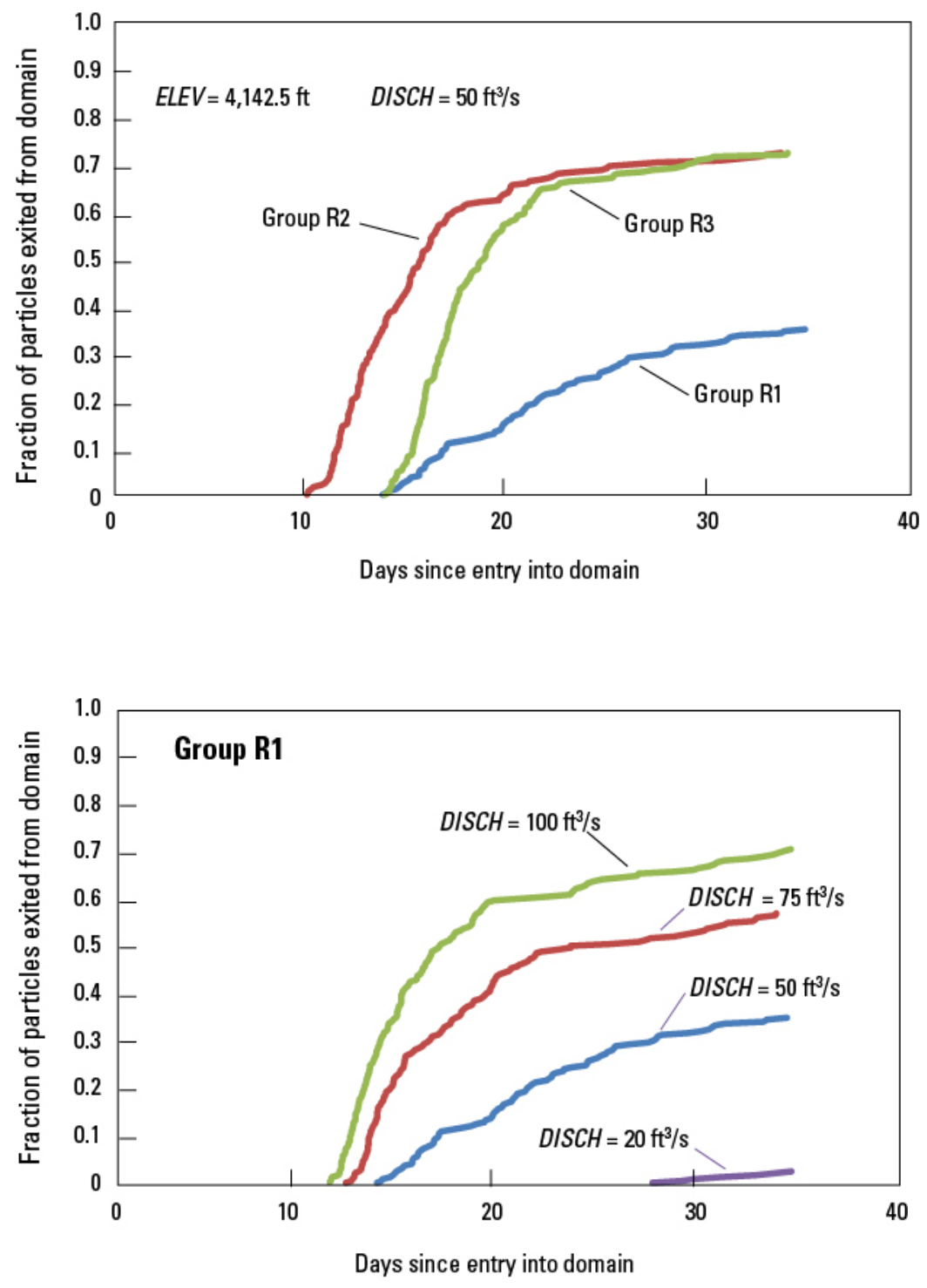

Figure 19. Graph showing fraction of particles that exited the model domain as a function of time since the particle group was inserted into the simulation, for particle groups inserted at the Williamson River boundary, Upper Klamath Lake, Oregon. In each case, the lake elevation (ELEV) was $4,142.5$ feet and the Williamson River discharge $(\mathrm{DISCH})$ was 50 cubic meters per second.
Figure 20. Graph showing fraction of particles that exited the model domain as a function of time since the particle group was inserted into the simulation, for particle group R1, inserted at the Williamson River boundary, Upper Klamath Lake, Oregon. In each case, the lake elevation was 4,142.5 feet. The comparison is across three Williamson River discharges (DISCH) from 20 to 100 cubic meters per second.

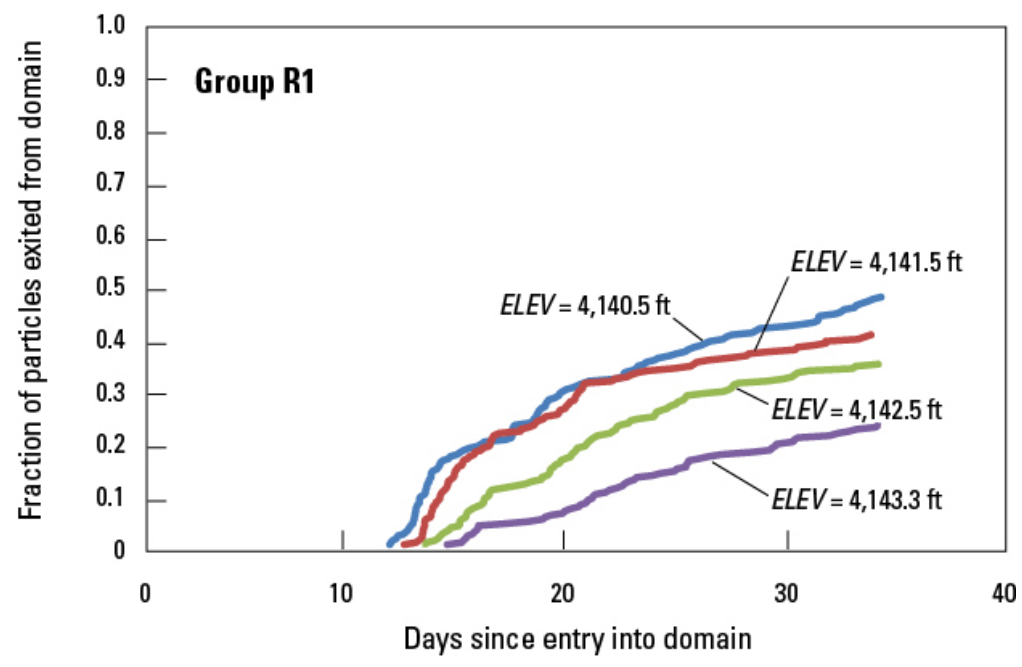

Figure 21. Graph showing fraction of particles that exited the model domain as a function of time since the particle group was inserted into the simulation, for particle group R1, inserted at the Williamson River boundary, Upper Klamath Lake, Oregon. In each case, the Williamson River discharge was 50 cubic meters per second. The comparison is across four lake elevations ( $E L E V$ ) from $4,140.5$ to $4,143.3$ feet. 
Particles released together as a group became increasingly dispersed with distance from the Williamson River. The particles tended to travel as a "cloud" southeast from the mouth of the Williamson River along the shoreline with the prevailing wind-driven circulation (see river release animations in the appendix). When the cloud reached the southern end of the lake, particles exited the domain rapidly at first, for a period of 1 to several days depending on conditions, and then the rate of exit slowed. In general, the effect of increasing lake elevation for a given combination of river discharge and wind scenario was to delay the start of the rapid phase of particles exiting the domain by 2-5 days, depending on wind conditions. For group R2 particles, that phase started about 10 days from the time of in- sertion, and, as a result, the cumulative fraction of particles that exited the domain by 10 days decreased with increasing elevation at all values of DISCH (table 7). For group R1 and R3 particles, the rapid phase of particle exit occurred later, and the cumulative exit of particles decreased with increasing ELEV at 15 days after insertion (table 7), particularly at the lowest values of DISCH. Beyond the initial rapid exit phase, however, the effect of lake elevation was small compared to the effect of wind conditions and river discharge, as particle pathways became complicated functions of lake elevation, discharge, and winddriven circulation patterns. This is demonstrated by the relation between lake elevation and the cumulative fraction of particles that exited by 25 days (table 7), for all particle groups.

Table 7. Fraction of particles that have exited the model domain as of 10,15 , and 25 days since the particle group was inserted into the simulation (blue bars), as a function of Upper Klamath Lake elevation and Williamson River discharge, for particle groups inserted at spawning grounds in the Williamson and Sprague Rivers, Oregon.

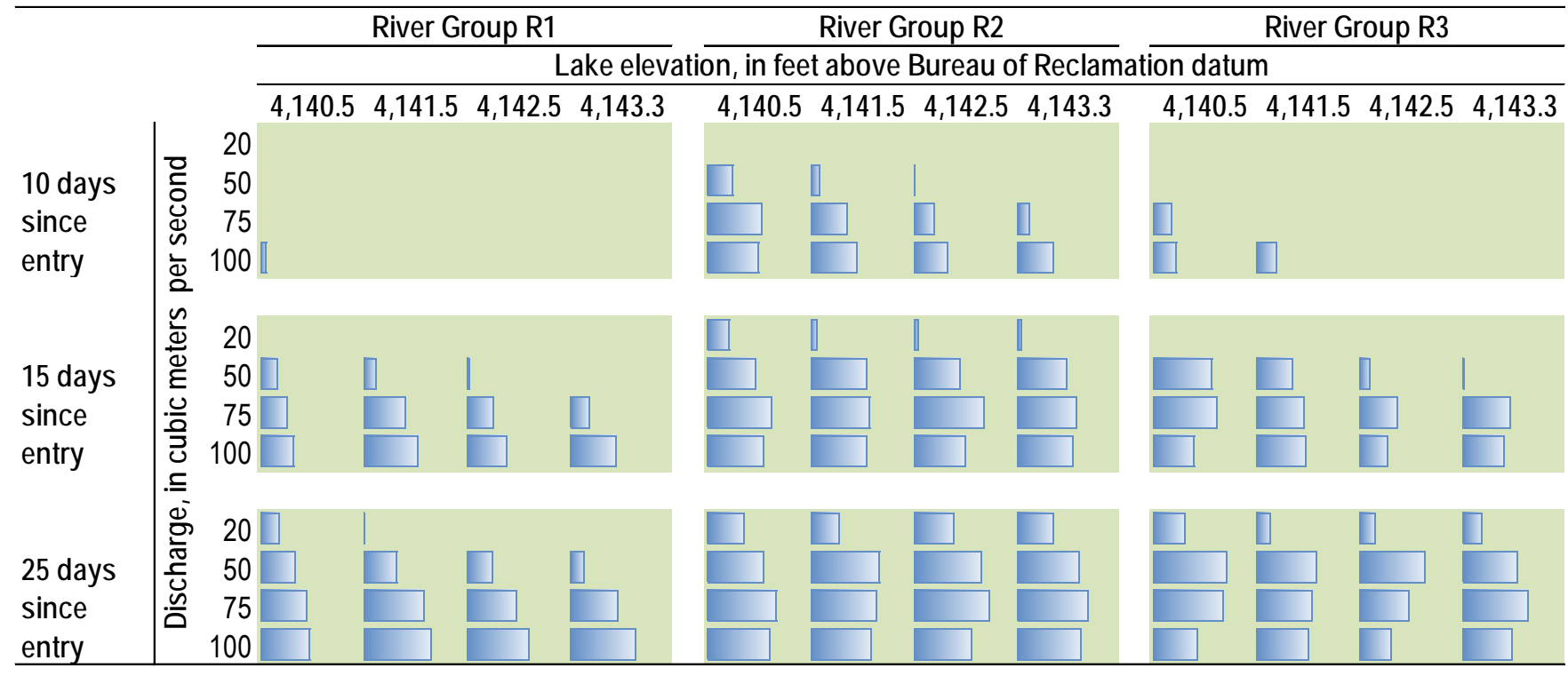




\section{Discussion}

We estimated the timing and relative magnitudes of the pulses of LRS and SNS larval drift in the Williamson River based on counts of radiotagged adult females returning to spawning grounds, using relationships developed with four years of data in which we had both adult counts and larval drift measurements. We estimated the timing of LRS larvae swimming up from shoreline springs based on the observed ratio of adult river-spawning to adult spring-spawning fish. The progression of CPUE through time is a way to track the entry of new larvae into the system, particularly in zone 1 (around the Williamson River Delta), which is the zone where most larvae enter the system. The comparison of CPUE of tracked particles through time with the change in CPUE of larval trawls in between the first and second sampling survey in zone 1 indicated that timing of the estimated boundary condition was as much as a week too late in 2011 and approximately correct in 2012. When the length distribution of larvae in net catches was paired with the length distribution of tracked particles at the corresponding time and location (during both survey dates and all larval trawl sites in 2011), the length bias in the tracked particles indicated that the timing of the estimated boundary condition was late by about 5 days, based on the length-at-age regression used in this study. On the basis of results from these 2 years, the estimate of the timing of the biggest pulse of LRS or SNS larvae (based on the counts of adult females returning to spawn) probably is not more accurate than plus or minus 5 days.

The comparison between the distribution of tracked particles and the distribution of larvae caught in larval trawls indicated that transport with wind-driven currents could explain some features of the net catches-notably the increased density of larvae along the eastern and western shorelines of Upper Klamath Lake. There were, however, differences between the distribution of tracked particles and the distribution of net densities that lead to unanswered questions. The density in larval trawls was higher, relative to other parts of the lake, in zone 2 (the northwestern part of the lake, including Ball and Shoalwater Bays) than was predicted by the particle tracking, because zone 2 is farther along the predominant (clockwise from the Williamson River Delta) transport pathways than either zones 3 or 4 . This was particularly true during the second (later June) sampling surveys in both 2011 and 2012; notable were particularly high density of both species in nets set in the far interior of Ball Bay during the June 20-23 survey in 2011. Nothing in the particle tracking indicates why there should be high densities so far from known spawning grounds.

The length of tracked particles, as determined from a length-at-age regression, and the length of fish caught in larval trawls indicated that the basic progression of length through time was consistent, at least as resolved with the two sampling surveys done in each year, and primarily resulted from the aging of larvae of both species that entered the system prior to the first sampling survey in each year. The particle tracking results indicate that (1) there should be very few SNS larvae in the lake in April or early May, (2) the median length of LRS larvae should increase through April and May as spring-spawned larvae mature but before river-spawned larvae enter the system, and (3) the median length of LRS larvae should decrease abruptly with the entry of a large pulse of river-spawned larvae in late May and progressively increase through time again thereafter. However, because larval trawl surveys took place in late May and June (May 23-27 and June 20-23, 2011; and June 11-15 and June 25-28, 2012), all sampling was done subsequent to the entry of most of the larvae into the lake, and this result of the particle tracking could not be tested.

The progression of lengths spatially through the lake could be compared on each survey date between the tracked particles and the larval trawl catches. The median length of tracked particles was always shortest in zone 1 around the Williamson River Delta, and usually the next-shortest 
median length was in zone 3 (next zone to the south). An exception was that zone 3 had the longest median length of particles representing LRS larvae in the May 25, 2011, survey, reflecting the spring-spawned fish in the lake that had aged through April and May. Although the length progression of the tracked particles through the zones lent itself to an uncomplicated interpretation, the length progression of the larvae caught in larval trawls was not simple. The median length of larvae in zone 1 was not, in general, the shortest, and lengths did not consistently increase between zones 1 and 3. On the June 22, 2011, survey date, the median length in the larval trawls was shortest in zone 4 and increased through zones $3,2,1$, and 0 , in the opposite direction of the predominant transport by currents. The length progression of net catches through the various zones of the lake were inconsistent on some sampling dates with the progression as simulated by the tracked particles, indicating that either (1) the larvae are not subject to passive transport through the lake by the currents, at least not to the extent simulated by the model, or (2) the larval trawls are not consistently collecting samples that are statistically representative of the length distributions at the time and location of the net set. The former indicates that our understanding of larval behavior still is limited; the latter could be due to the small numbers of larvae that are caught, which is as predicted if the larvae are dispersed passively throughout the lake, or an unknown bias in recruitment to the sampling gear. This discrepancy cannot be resolved with the data used in this study, but points to the need for a better understanding of both behavior and gear efficiencies.

When spatial and temporal variation was combined by pairing the length distribution of larvae in net catches with the length distribution of tracked particles at the corresponding time and location, during both survey dates and all larval trawl sites for the purpose of quantifying correlation, the Spearman $\rho$ was significant $(p<0.05)$ for both LRS and SNS larvae (0.33 and 0.60, respectively) in 2011 and for LRS but not SNS larvae in
2012 (Spearman $\rho=0.37$ ). Given the separate analyses of the temporal and spatial progression of median lengths, the significant correlations are dominated by the progression of lengths through time between the sampling surveys as larvae within the lake age.

Interpretation of the particle retention experiments requires that care be taken not to interpret the exit rates as actual emigration rates that apply to larval suckers - most importantly because larval suckers experience high mortality and, therefore, emigration as a fraction of the total larvae entering the system always will be much less than the rates shown in the particle retention experiments in this study. In 2012 for example, Simon and others (2013) conservatively estimated that total entrainment to the A-Canal and Link River was equivalent to 4 days (shortnose suckers) or 4.5 days (Lost River suckers) of systemwide mortality. However, as quantitative measures of relative emigration, when compared among the experiments at different conditions, the rates are useful. Not surprisingly, the exit rates of particles inserted at springs were higher than those of particles inserted in the river because particles inserted at the springs were closer to the outlet of the lake to start. Markle and others (2009) also noted that larvae with early hatch dates (which are more likely to be springspawned fish) had a greater chance of leaving the lake. At 15 days after insertion into the model, and depending on the conditions, between about $2 \%$ and $100 \%$ of the particles inserted at the springs had left the model domain at the lake outlet. At 25 days after insertion, between about $0 \%$ and $77 \%$ of the particles inserted at the river had exited.

The two conditions that most influenced how fast particles began to exit the domain, and how soon the exit of particles slowed, were (1) river discharge, and (2) wind speed and direction. Higher discharge led to more rapid exiting of particles, whether inserted at the springs or in the river. At $75 \mathrm{~m}^{3} / \mathrm{s}$, retention of particles inserted in the river was between 23 and $53 \%$ at 25 days after insertion; at $100 \mathrm{~m}^{3} / \mathrm{s}$, retention was between 
32 and 67 percent. At the other end of the discharge range, at the lowest discharge tested (20 $\mathrm{m}^{3} / \mathrm{s}$ ), the retention of particles inserted in the river was between 60 and $100 \%$ at 25 days after insertion, depending on other conditions. Counter-prevailing winds, even for a few days, delayed the onset of the exit of particles, and because the particles were more dispersed, such winds slowed the rate of exit of the particles as well. The combination of low discharge $\left(20\right.$ or $\left.50 \mathrm{~m}^{3} / \mathrm{s}\right)$ and a few days of counter-prevailing winds resulted in the highest retention for particles inserted in the river, between 64 and $100 \%$ at 25 days after insertion. This also was the only combination of conditions for which the effect of lake elevation still was significant and predictable (such that retention increased as lake elevation increased) at 25 days after insertion. This combination of river discharge and wind is not unlikely in May - the 50th percentile of monthly mean Williamson River discharge in May during the period of record was about $42 \mathrm{~m}^{3} / \mathrm{s}$ and the wind scenario used in the simulation was measured during May 125, 2009 - so it may be appropriate to assume that the retention of river-spawned larvae would be at the high end of the range (after taking into account mortality) in many years. Consistent northwesterly winds with no reversal hastened the onset of the exit of particles, and strong winds in a prevailing direction hastened the exit even more.

The effect of lake elevation was superimposed on the effects of river discharge and winds, such that higher lake elevation delayed the onset of the exit of particles for the same set of conditions. This was true for particles inserted at the springs (delay of 1-2 days) and particles inserted in the river (delay of 3-4 days). Beyond this short time window, however, the effect of lake elevation on overall retention was small and, for the reasons discussed below, unpredictable. With regard to the management of lake elevation, the results of the particle-retention experiments show that this would only be an effective tool to increase retention under a limited (although not uncommon) combination of conditions, and un- der these conditions retention is likely to be high in any case.

The pathways of particles that have been in the model domain for several days, and how dispersed a group of particles becomes, is a result of interactions of elevation, river discharge, and wind forcing, such that the retention outcome becomes an unpredictable function of any individual factor. Depending on wind conditions, this was evident by $8-10$ days after insertion for the particles inserted at the springs and by 15-25 days after insertion for particles inserted in the river. Discharge and elevation affect the timing of the interaction of a swarm of particles with the wind-driven circulation, which varies day-to-day and on a diel basis (Wood and others, 2008). One place where this becomes particularly important is at the base of Modoc Rim, across from Sesti Tgawaals Point, where the prevailing clockwise wind-driven circulation has an east-to-west component. When the circulation is strong, that eastto-west component is strong, and when the circulation is weak, that east-to-west component is weak, and the along-shore current is relatively more prominent. Examination of the movement of particles showed that much of the unpredictability in the retention results comes from the fact that particles can either traverse the lake from east to west in large numbers (which they will do if the east-to-west component of the circulation is strong), or they can move south of Buck Island and out of the lake in large numbers (which they will do if the along-shore current is relatively strong in comparison to the east-to-west component of the circulation). The timing of a swarm of particles moving down the eastern shoreline can greatly affect the number of particles that take one route or the other because the wind-driven circulation is so variable. The retention of particles inserted at the springs becomes unpredictable sooner than the retention of particles inserted in the river because they start out at the base of Modoc Rim close to this area of the lake.

The limitations of this individual-based model are several and were discussed in Wood and others (2014) — incomplete understanding of 
fish swimming behavior, unknown speciesspecific and age- or location-dependent mortality rates, and differential growth rates. In this study, an additional challenge was the lack of detailed measurements of fish density at the river boundary. Given these limitations, we did not attempt to further validate the model with the field data, but rather used the model results as context for the interpretation of the field data and to suggest appropriate areas for future inquiry. This study made progress on the challenging problems of (1) estimating larval drift boundary conditions for endangered suckers, (2) using an individualbased model for larval fish to inform the interpretation of field data, and (3) using the model to investigate larval dispersion under a matrix of environmental conditions. The study had moderate success in addressing all three problems, indicating that further progress on these problems is possible and that further research may produce helpful results. This study also provides confidence that the individual-based model developed for Upper Klamath and Agency Lakes can be used to investigate the broad patterns of larval dispersal in this system and to simulate the effect of a proposed management strategy.

\section{References Cited}

Casulli, Vincenzo, and Zanolli, P., 2002, Semiimplicit numerical modeling of nonhydrostatic free-surface flows for environmental problems: Mathematical and Computer Modelling, v. 36, p. 1131-1149.

Chambers, J.M., and Hastie, T.J., eds., 1992, Statistical models in S: Pacific Grove, California, Wadsworth and Brooks/Cole Advanced Book and Software, $608 \mathrm{p}$.

Ellsworth, C.M., and Martin, B.A., 2012, Patterns of larval sucker emigration from the Sprague and lower Williamson Rivers of the Upper Klamath Basin, Oregon, after the removal of Chiloquin Dam -2009-10 Annual Report: U.S. Geological Survey Open-File Report 20121037, 34 p., http:/pubs.usgs.gov/of/2012/1037/.
Erdman, C.S., and Hendrixson, H.A., 2010, Larval Lost River and shortnose sucker response to large scale wetland restoration at the Williamson River Delta preserve-2009 annual data summary: Klamath Falls, Oreg., The Nature Conservancy, $38 \mathrm{p}$.

Foott, J.S., Stone, R., and Wilkens, A., 2013, Juvenile Lost River sucker sentinel survival in Upper Klamath Lake mesocosm cages - July 2012-March 2013: U.S. Fish and Wildlife Service, California Nevada Fish Health Center, accessed January 14, 2014, at http://www.fws.gov/canvfhc/reports.asp.

Graham Matthews and Associates, 2009, Fourmile-Sevenmile restoration assessment project: Weaverville, California, prepared for U.S. Fish and Wildlife Service, Klamath Falls, Oregon, $138 \mathrm{p}$.

Hewitt, D.A., Janney, E.C., Hayes, B.S., and Harris, A.C., 2012, Demographics and run timing of adult Lost River (Deltistes luxatus) and shortnose (Chasmistes brevirostris) suckers in Upper Klamath Lake, Oregon, 2011: U.S. Geological Survey Open-File Report 2012-1193, 42 p., http://pubs.usgs.gov/of/2012/1193/.

Markle, D.F., Reithel, S.A., Crandall, J., Wood, T., Tyler, T.J., Terwilliger, M., and Simon, D.C., 2009, Larval fish transport and retention and the importance of location for juvenile fish recruitment in Upper Klamath Lake, Oregon: Transactions of the American Fisheries Society, v.138, p. 328-347.

Martin, B.A., Hewitt, D.A., and Ellsworth, C.M., 2013, Effects of Chiloquin Dam on spawning distribution and larval emigration of Lost River, shortnose, and Klamath largescale suckers in the Williamson and Sprague Rivers, Oregon: U.S. Geological Survey Open-File Report 2013-1039, 28 p., http://pubs.usgs.gov/of/2013/1039/.

Simon, D.C., Terwilliger, M.R., and Markle, D.F., 2013, Annual report for project, "Larval and juvenile ecology of Upper Klamath Lake suckers: 2012": Great Basin Cooperative Ecosystems Studies Unit Agency Program 
USBR\#2-FG-81-0813, submitted to Bureau of Reclamation, Klamath Falls, Oregon, 88 p.

Terwilliger, M.R., Markle, D.F., and Kann, Jacob, 2003, Associations between water quality and daily growth of juvenile shortnose and Lost River suckers in Upper Klamath Lake, Oregon: Transactions of the American Fisheries Society, v. 132, p. 691-708.

Wood, T.M., Cheng, R.T., Gartner, J.W., Hoilman, G.R., Lindenberg, M.K., and Wellman, R.E., 2008, Modeling hydrodynamics and heat transport in Upper Klamath Lake, Oregon, and implications for water quality: U.S. Geological Survey Scientific Investigations Report 20085076, 48 p.,

http://pubs.usgs.gov/sir/2008/5076/.
Wood, T.M., Hendrixson, H.A., Markle, D.F., Erdman, C.S., Burdick, S.M., and Ellsworth, C.M., 2014, Simulation and validation of larval sucker dispersal and retention through the restored Williamson River Delta and Upper Klamath Lake system, Oregon: U.S. Geological Survey Scientific Investigations Report 20135194, 34 p., http://dx.doi.org/10.3133/sir20135194.

Wood, T.M., Hendrixson, H.A., Markle, D.F., Erdman, C.S., Burdick, S.M., Ellsworth, C.M., and Buccola, N.L., 2012, Dispersal of larval suckers at the Williamson River Delta, Upper Klamath Lake, Oregon, 2006-09: U.S. Geological Survey Scientific Investigations Report 2012-5016, 28 p., http://pubs.usgs.gov/sir/2012/5016/. 


\section{Appendix A. Animations of Particle Tracking Simulations, April-June, 2011-12}

Videos in .avi format are available for download at http://pubs.usgs.gov/of/2014/1061.

\section{Particle ages during 2011:}

LRS River Spawned Fish-Animation of particle tracking simulation between May 15 and June 24, 2011. Particles represent Lost River sucker larvae entering the simulation at the Modoc Point Road bridge.

SNS River Spawned Fish-Animation of particle tracking simulation between May 15 and June 24, 2011. Particles represent shortnose sucker larvae entering the simulation at the Modoc Point Road bridge.

LRS Spring Spawned Fish-Animation of particle tracking simulation between April 15 and June 10, 2011. Particles represent Lost River sucker larvae entering the simulation at springs along the eastern shoreline.

\section{Particle ages during 2012:}

LRS River Spawned Fish-Animation of particle tracking simulation between May 18 and June 29, 2012. Particles represent Lost River sucker larvae entering the simulation at the Modoc Point Road bridge.

SNS River Spawned Fish-Animation of particle tracking simulation between May 16 and June 29, 2012. Particles represent shortnose sucker larvae entering the simulation at the Modoc Point Road bridge.

LRS Spring Spawned Fish-Animation of particle tracking simulation between April 21 and June 11, 2012. Particles represent Lost River sucker larvae entering the simulation at springs along the eastern shoreline. 
This page is intentionally blank 
产

웋

क

गั. 